\author{
UNIVERSIDADE DE SÃO PAULO \\ Faculdade de Filosofia, Ciências e Letras de Ribeirão Preto \\ Departamento de Psicologia e Educação \\ Programa de Pós-Graduação em Psicobiologia
}

\title{
EFEITOS DA DESNUTRIÇÃO PROTÉICA PRECOCE E DA ESTIMULAÇÃO AMBIENTAL EM MEDIDAS BIOQUÍMICAS E COMPORTAMENTAIS EM RATOS
}

Roberto de Oliveira Soares

Ribeirão Preto

2009 
UNIVERSIDADE DE SÃO PAULO

Faculdade de Filosofia, Ciências e Letras de Ribeirão Preto

Departamento de Psicologia e Educação

Programa de Pós-Graduação em Psicobiologia

\title{
EFEITOS DA DESNUTRIÇÃO PROTÉICA PRECOCE E DA ESTIMULAÇÃO AMBIENTAL EM MEDIDAS BIOQUÍMICAS E COMPORTAMENTAIS EM RATOS
}

\author{
Roberto de Oliveira Soares \\ Prof. Dr. Sebastião de Sousa Almeida
}

Dissertação apresentada à Faculdade de Filosofia, Ciências e Letras de Ribeirão Preto, como parte das exigências para obtenção do título de Mestre em Ciências, área de Psicobiologia. 
AUTORIZO A REPRODUÇÃO E DIVULGAÇÃO TOTAL OU PARCIAL DESTE TRABALHO, POR QUALQUER MEIO CONVENCIONAL OU ELETRÔNICO, PARA FINS DE ESTUDO E PESQUISA, DESDE QUE CITADA A FONTE.

\section{FICHA CATALOGRÁFICA}

Soares, Roberto de Oliveira

Efeitos da desnutrição protéica precoce e da estimulação ambiental em medidas bioquímicas e comportamentais em ratos. Ribeirão Preto, 2009.

65 p. : il. ; $30 \mathrm{~cm}$

Dissertação de Mestrado, apresentada à Faculdade de Filosofia, Ciências e Letras de Ribeirão Preto/USP. Área de concentração: Psicobiologia.

Orientador: Almeida, Sebastião de Sousa.

1. Desnutrição protéica precoce. 2. Estimulação ambiental.

3. Estimulação táctil. 4. Enriquecimento ambiental. 5. Labirinto em cruz elevado. 6. Bioquímica. 7. Comportamento. 8. Ratos. 


\section{FOLHA DE APROVAÇÃO}

Roberto de Oliveira Soares

"Efeitos da desnutrição protéica precoce e da estimulação ambiental em medidas bioquímicas e comportamentais em ratos"

Dissertação apresentada à Faculdade de Filosofia, Ciências e Letras de Ribeirão Preto da USP, como parte das exigências para a obtenção do título de Mestre em Ciências. Área: Psicobiologia.

Aprovado em:

Banca Examinadora

$\operatorname{Prof}(\mathrm{a}) . \operatorname{Dr}(\mathrm{a})$.

Instituição:

Assinatura:

$\operatorname{Prof}(\mathrm{a}) . \operatorname{Dr}(\mathrm{a})$.

Instituição:

Assinatura:

$\operatorname{Prof}(\mathrm{a}) . \operatorname{Dr}(\mathrm{a})$.

Instituição:

Assinatura: 
A minha Avó Leonidia Fagundes da Silva, que mesmo sem saber ler o próprio nome, foi à maior incentivadora para a educação que eu já conheci, e que graças ao esforço dela eu pude chegar até aqui.

Ao professor Luiz Marcellino de Oliveira, que além de professor, foi um grande amigo. 


\section{AGRADECIMENTOS}

Ao Prof. Dr. Luiz Marcellino de Oliveira, professor e amigo, que me ensinou não só a fazer pesquisa como também ser um professor, dentro e fora da sala de aula. E que me ensinou a seguir em frente, mesmo quando as condições não são favoráveis.

Ao Prof. Dr. Sebastião de Sousa Almeida, pela acolhida no momento de necessidade e por acreditar, refinar e investir nas minhas idéias, dando chance de caminhar um pouco mais na pesquisa e na sala de aula.

Aos meus pais Paulo Roberto e Rute, meus heróis, meus exemplos, minha história e minha meta.

Aos meus irmãos, Sandra e Mau, mesmo privado de sua companhia, vocês fazem parte do meu dia a dia.

Ao Dalmo, Técnico do laboratório de Nutrição e Comportamento, que além da incomparável ajuda na pesquisa, me ensinou muito a respeito do meu sujeito de pesquisa.

Ao Valdomiro e a Priscila, essa pesquisa também é resultado do trabalho deles.

Aos amigos Marcelo, Edson, Juliana e Karla. Amigos de dentro e principalmente de fora da universidade.

A "família" do Laboratório de Nutrição e Comportamento: Gisele, Marisa, Paula, Lucas, Natália, Mariana, Fernanda. Vocês são incríveis e a ajuda de todos foi fundamental!

À Fundação de Amparo à Pesquisa do Estado de São Paulo - FAPESP, pelo financiamento deste trabalho. 
"Ó Deus de meus pais, eu te dou graças e te louvo, porque me deu sabedoria e força..."

Dn 2:23 
Resumo

O déficit na ingestão de proteína durante o período de rápido desenvolvimento do sistema nervoso central resulta em atrasos no desenvolvimento físico e cerebral, com conseqüências para o comportamento de ratos. Estudos mostram que prejuízos causados pela desnutrição podem ser parcialmente revertidos pelo enriquecimento ambiental e pela estimulação táctil. $\mathrm{O}$ enriquecimento ambiental aumenta a exploração no labirinto em cruz elevado (LCE), além de reverter alguns danos no cérebro de ratos desnutridos. $\mathrm{O}$ objetivo do presente trabalho foi comparar, em ratos desnutridos (D) e bem nutridos (C), os efeitos do enriquecimento ambiental (E) e da estimulação táctil $(\mathrm{H})$ durante o período de formação do SNC (8 a 35 dias), através do desempenho no LCE aos 36 e 37 dias de idade. Os ratos foram divididos em dois diferentes grupos de acordo com a dieta: desnutridos (dieta com 6\% de proteína) e controles (dieta com $16 \%$ de proteína). Também foram subdivididos em grupos conforme a manipulação ambiental: não estimulação $(\mathrm{N})$, ambiente enriquecido $(\mathrm{E})$, e estimulação táctil (H). A manipulação ambiental foi realizada nos períodos de 8 a 35 dias. Após os testes comportamentais os animais foram decapitados e tiveram o hipocampo e córtex occipital extraído para a análise de poliaminas através do método do HPLC, e o sangue foi retirado para a análise de corticosterona plasmática através da técnica de radioimunoensaio. Os dados evidenciaram que os animais D apresentaram menor peso corporal quando comparados com os animais C. A partir da exposição ao LCE, os resultados mostram que D permanecem uma maior porcentagem $(p<0,05)$ de tempo e entram mais nos braços abertos em relação a $C$. Com relação às diferentes estimulações, os animais DE apresentaram uma menor percentagem $(\mathrm{P}<0,05)$ de tempo nos braços abertos quando comparados aos animais $\mathrm{DH}$ e animais $\mathrm{DN}$. Os animais $C$ apresentam uma atividade locomotora maior que $D(p<0,05)$, demonstrado pelo maior numero de entradas nos braços fechados. Também foi possível verificar que $\mathrm{D}$ possui maiores níveis de corticosterona plasmática comparado a $\mathrm{C}$. Também foi possível verificar que animais $\mathrm{N}$ possuem maior quantidade de espermidina (SPD), espermina (SPM) e SPD+SPM no hipocampo quando comparados com animais estimulados, independente da dieta a que foram expostos. Os dados do presente estudo sugerem que tanto a manipulação táctil como o enriquecimento ambiental amenizam as alterações produzidas pela desnutrição no comportamento de exploração dos braços abertos do LCE, além de alterarem a resposta de poliaminas no hipocampo durante a $2^{\mathrm{a}}$ exposição ao LCE.

Palavras-chave: desnutrição protéica precoce, estimulação ambiental, estimulação táctil, enriquecimento ambiental, labirinto em cruz elevado, bioquímica, comportamento, ratos. 


\begin{abstract}
Low protein ingestion during the brain growth spurt results in physical and cerebral deficits of development with long-lasting consequences for the behavior of rats. It has been show that impairments caused by protein malnutrition can be partially reverted by environmental enrichment and tactile stimulation. Environmental enrichment increases the exploration in the elevated plus-maze (EPM), and reverts some brain impairments produced by malnutrition. The objective of the present study was to compare effects of the environmental enrichment $(\mathrm{E})$ and tactile stimulation $(\mathrm{H})$ in malnourished (D) and wellnourished (C) rats, during the period of development of SNC (8 to 35 days), upon the behavior of rats in EPM at the ages of 36 and 37 days. The rats were divided in two different groups according to the diet: protein malnutrition (6\% of protein) and controls $(16 \%$ of protein). They were also subdivided according to the environmental manipulation: N, E and $\mathrm{H}$. The environmental manipulation was accomplished from 8 to 35 days. After the behavioral tests, the rats were decapitated, and the hippocampus and occipital cortex removed for polyamines analysis by HPLC method, and the blood was collected for analysis of plasmatic corticosterone by radioimmunoassay technique. The results showed that $\mathrm{D}$ animals presented lower body weight than $\mathrm{C}$ animals. The EPM test showed that D animals enter and stay more time in the open arms than $\mathrm{C}$ animals $(\mathrm{p}<0.05)$. Regarding the different environmental stimulations, the DE animals presented a lower percentage of time in the open arms when compared to $\mathrm{DH}$ and $\mathrm{DN}$ animals $(\mathrm{p}<0.05)$. The $\mathrm{C}$ rats presents increases in the motor activity than D ( $\mathrm{p}<0.05)$, as demonstrated by higher number of closed arm entries Regarding the biochemical analysis it was showed higher levels of plasmatic corticosterone concentrations in $\mathrm{D}$ as compared to $\mathrm{C}$ animals. It was also showed that non-stimulated animals presented higher levels of spermidine (SPD), spermine (SPM) and SPD+SPM in the hippocampus when compared with stimulated ones, irrespective to the diet conditions. The present data suggest that both the tactile handling and the environmental enrichment reduced the behavioral alterations produced by early malnutrition in the exploration of the open arms in the EPM, as well as, altered the polyamines response in the hippocampus during the second trial in the EPM.
\end{abstract}

Key words: early protein malnutrition, environmental stimulation, handling, environmental enrichment, elevated plus-maze, biochemistry, behavior, rats. 


\section{Sumário}

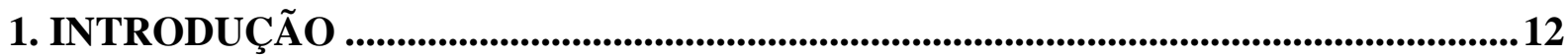

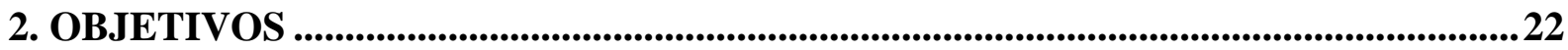

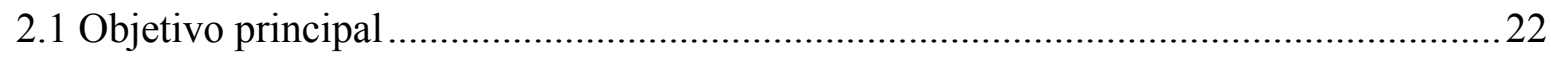

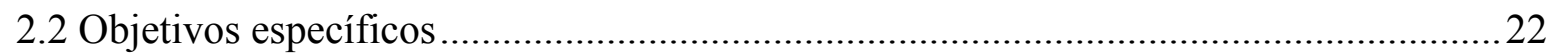

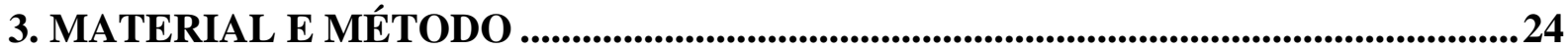

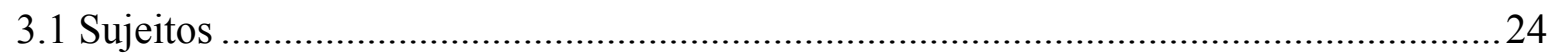

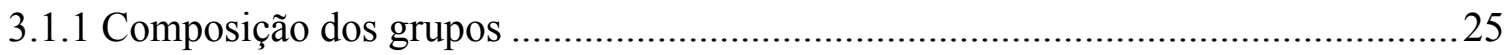

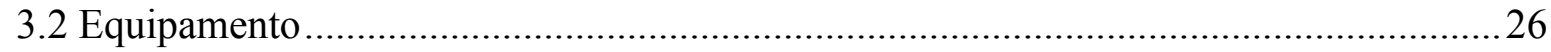

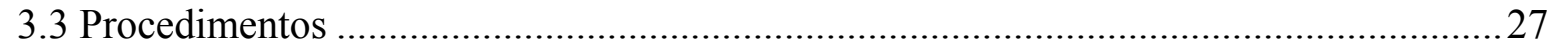

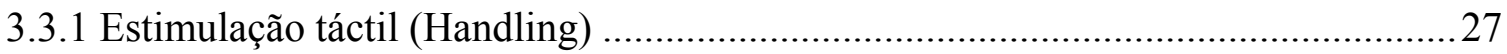

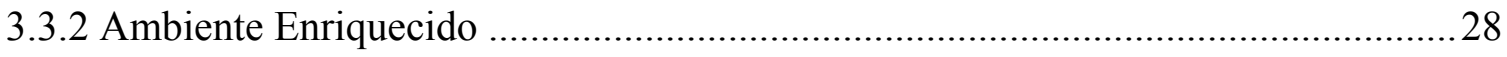

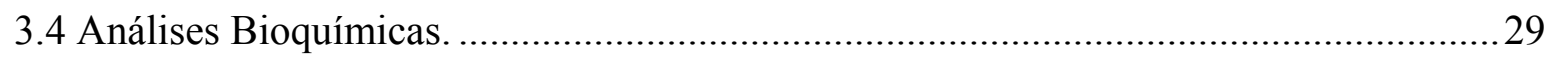

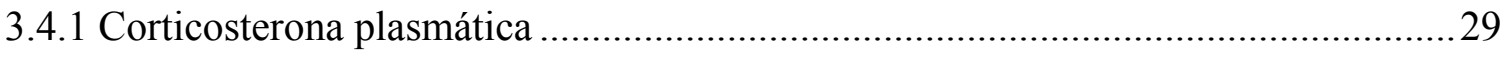

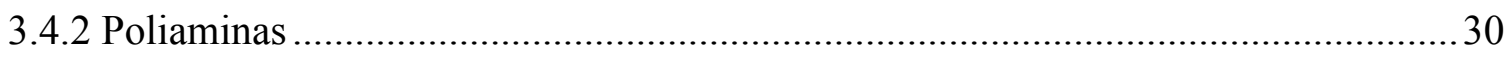

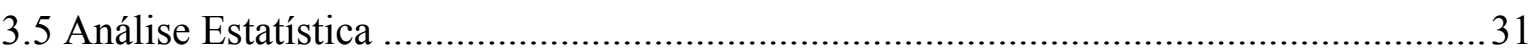

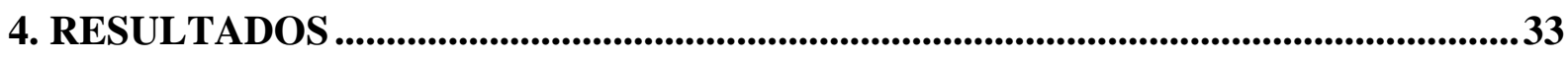

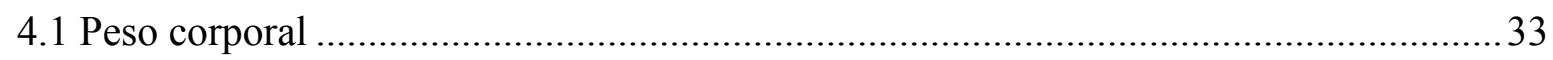

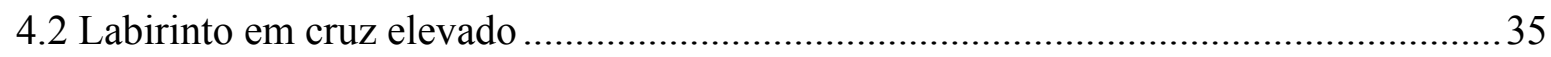

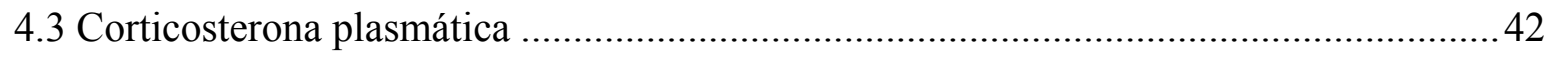

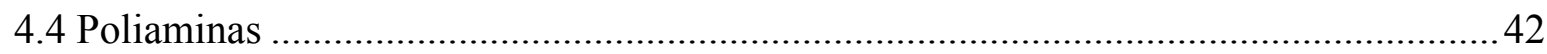

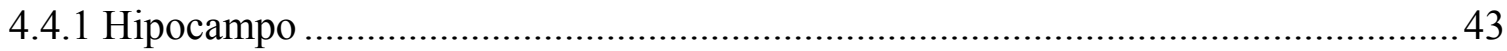

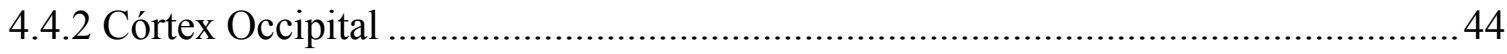




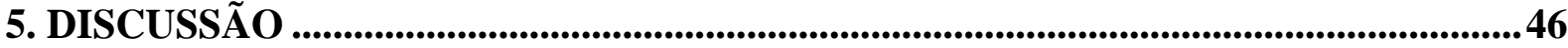

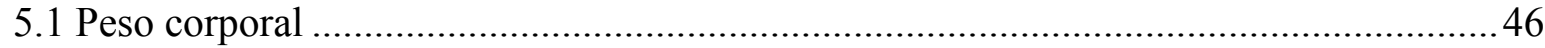

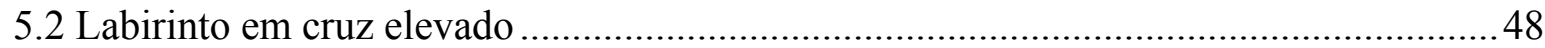

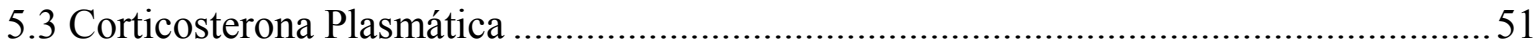

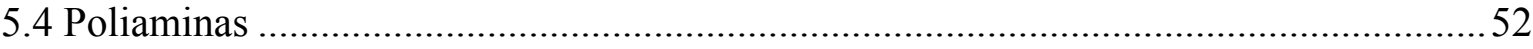

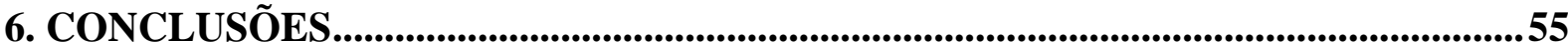

REFERÊNCIAS BIBLIOGRÁFICAS …...........................................................................5 


\section{INTRODUÇÃO}

O termo "má nutrição" implica que um ou mais nutrientes estão ausentes na dieta ou são oferecidos em uma quantidade inadequada (Morgane et 2002). A má-nutrição é um problema mais grave quando afeta recém-nascidos e crianças durante os estágios mais vulneráveis de seu desenvolvimento cerebral, comprometendo diversos eventos maturacionais, resultando em alterações morfológicas, neuroquímicas, comportamentais e cognitivas. (Levitsky e Barnes, 1972). A proteína é essencial para o crescimento e manutenção do organismo, e sua falta ocasiona a desnutrição (UNICEF, 1998). No mundo muitas crianças são afetadas pela desnutrição, que junto com outras epidemias como a malária, por exemplo, é responsável pelo alto número de mortalidade infantil (UNICEF, 2007).

As proteínas são formadas por agrupamentos de aminoácidos resultantes da ingestão de dietas e são necessárias para diversas funções do sistema nervoso central (SNC). Assim, os déficits de proteína podem afetar diretamente o desenvolvimento cerebral (Lima et al, 1993; Morgane et al, 2002).

As alterações provocadas pela desnutrição podem variar conforme a espécie (Smart, 1977; Smart, et al 1974). Em ratos, o déficit na ingestão de proteína durante o período de gestação pode resultar em atrasos no desenvolvimento físico e cerebral. (Santucci et al, 1994; Cintra et al, 1997; Almeida et al 1996; Morgane et al 2002). Na desnutrição podem ser observadas alterações bioquímicas e neurológicas (Hermel et al, 2001; Feoli et al, 2006), resultando também em alterações comportamentais (de Oliveira, 1985; Riul et al, 1999) e atrasos em funções intelectuais e cognitivas (Barnes, 1976; Brozek, 1979, 1983, Wainwright e Colombo, 2006).

Dentre os inúmeros modelos experimentais de desnutrição um dos mais utilizados é o de desnutrição protéica, sendo que esta desnutrição pode ser imposta no período pré-natal, no 
período pós-natal, ou em ambos. Conforme o período em que a desnutrição é imposta, podem resultar em diferentes conseqüências para os organismos. No período pré-natal a desnutrição pode alterar a plasticidade hipocampal (Kehoe, 2001), a neurogênese no giro denteado, o número de espinhas sinápticas e as células granulares e piramidais da região CA1 do hipocampo (Cintra et al, 1997, Duran et al, 2006).

O período em que a desnutrição é imposta é extremamente importante. A desnutrição pósnatal imposta durante o período do desenvolvimento do SNC é extremamente prejudicial ocasionando efeitos irreversíveis (de Oliveira e Almeida, 1983; Morgane et al, 2002; Silva e De Oliveira, 2005). Em ratos, o período que consiste no pico do desenvolvimento do sistema nervoso central é entre os 7 e 14 dias de vida, perdurando até os 35 dias (Morgane et al, 2002). Durante este período estão ocorrendo fenômenos como neurogênese, gliogênese e pico de mielinização, em diferentes regiões do cérebro (Levitsky \& Barnes, 1972; Morgane et al., 1992 e 2002).

Ratos desnutridos, quando comparados a ratos bem-nutridos apresentam menor quantidade de DNA e RNA, redução da ramificação dendrítica (Will et al, 2004), redução do número de terminais sinápticos, bem como redução de mielinização em todo SNC (Lima et al, 1999). A desnutrição pode aumentar o nível de corticosteróide circulante após a exposição ao estresse. (Adlard e Smart, 1972), embora não tenha sido relatada alterações nas concentrações plasmáticas deste hormônio, até então, entre controles e desnutridos. Ratos desnutridos, de acordo com Almeida e colaboradores (1992), apresentaram baixa atividade locomotora, demonstrado pela redução de entradas nos braços fechados no labirinto em cruz elevado (LCE), quando comparados com ratos bem-nutridos. Também foi observado, no teste do LCE, o aumento no número de visitas e tempo gasto na extremidade do braço aberto em ratos desnutridos, quando comparados a ratos controle (Almeida et al, 1993; e Fraçolin-Silva et al, 2006). 
Os glicocorticóides são geralmente catabólicos, inibindo a divisão celular, síntese protéica e captação de aminoácidos e glicose pelos tecidos. As conseqüências destes eventos são potencialmente sérias para um organismo, durante o período no qual predomina o anabolismo. No sistema nervoso central (SNC), a elevação de corticosterona mediada pelo estresse contribui para a atrofia hipocampal, mas não é suficiente para causar morte neuronal (Lister et al, 2005; Kehoe, et al 2001; Mesquita, et al. 2003 e Schertel et al. 1991).

Sabe-se também que o nível de corticosterona pode ser alterado pela desnutrição, sugerindo que a desnutrição pode modificar a resposta adrenocortical ao estresse (Adlard, 1972). Agindo como agente de estresse crônico no rato (Kehoe, et al 2001; Duran et al 2006) a desnutrição protéica prolongada pode levar a uma diminuição da expressão do receptor de serotonina 5-HT1 A e da neurogênese no SNC (Lister et al, 2005).

A desnutrição protéica pode produzir a atrofia hipocampal e diminuição do número de receptores de glicocorticóides no hipocampo, com conseqüentes alterações na regulação da retroalimentação negativa da corticosterona sobre o eixo hipotálamo-hipófise-adrenal (HPA). Além disso, produz mantida elevação do hormônio adrenocorticotrófico (ACTH) e corticosterona circulante (Kehoe, et al 2001), assim como baixos níveis de fator trófico neural (BDNF) (Mesquita, et al. 2002).

A desnutrição também diminui a atividade da enzima ornitina descarboxilase (ODC) (Schertel et al. 1991), interferindo diretamente na síntese de poliaminas. As poliaminas são cátions alifáticos de baixo peso molecular ocorrendo em quase todas as células do organismo do rato. Esses cátions são a putrescina, a espermidina espermina. A putrescina é sintetizada nos mamíferos a partir da $L$-ornitina em uma reação catalisada pela ornitina descarboxilase (ODC), enzima limitante da síntese de poliaminas. A putrescina e a s-adenosilmetionina descarboxilada são substratos para a síntese de espermidina, que é precursora da espermina (Wallace, 2000). 
As poliaminas atuam como segundo mensageiro, nutriente, regulador metabólico, fator de crescimento, antioxidante, estabilizador de DNA, RNA e de membranas. Participam da modulação de eventos sinápticos plásticos, atuando na regulação da atividade bioquímica de proteínas, além de possuir atividade protetora contra o estresse (Rhee et al, 2007), sendo esta atividade protetora conhecida como a resposta de poliaminas ao estresse. A resposta de poliaminas ao estresse, segundo Gilad e colaboradores (2001), é a ativação do metabolismo das poliaminas frente ao aumento de glicocorticóides. Dessa maneira, quando há o aumento de corticosterona (glicocorticóide), as poliaminas podem apresentar queda de seus níveis, caracterizando o aumento do processo catabólico, reduzindo os níveis de poliaminas intracelular (Seiler, 2004).

Isso demonstra que as poliaminas têm papel fundamental no controle homeostático, atuando na capacidade do organismo em se adaptar a situações de estresse. Tal adaptação é chamada de resposta das poliaminas ao estresse, podendo esta ser maior quando houver uma reapresentação do estímulo após uma pausa temporal (Gilad et al, 1998). No entanto, sob uma condição permanente de estresse, como a desnutrição, por exemplo, as respostas das poliaminas ao estresse podem ser falhas, ou mal-adaptativas (Gilad e Gilad, 1996; Gilad et al, 2001).

A espermina e a espermidina podem modular a função de receptores de glutamato do tipo N-metil-D-aspartato (NMDA) de modo positivo ou negativo. Baixas concentrações de poliaminas acentuam as correntes evocadas pelos canais iônicos NMDA, enquanto altas concentrações de poliaminas inibem estes receptores (Wallace, 2003). Em animais que passam por situação de estresse, as poliaminas, mais exatamente a putrescina, apresentam um aumento em seus níveis, devido ao aumento da atividade da ornitina descarboxilase (ODC) (Gilad et al, 2001). As poliaminas são fundamentais para o crescimento celular e, se o crescimento celular é impedido, pode resultar em perda de poliaminas (Wallace, 2003). 
Como visto a desnutrição pode resultar em prejuízos comportamentais, cognitivos e biológicos, sendo que neste último pode se estender a níveis celulares (como no caso das poliaminas). Estudos têm mostrado que a "reversão" dos prejuízos causados pela desnutrição não são completamente recuperados através da reabilitação nutricional (de Oliveira e Almeida, 1985 e Riul et al, 1999). Por outro lado os prejuízos da desnutrição podem ser revertidos pela estimulação ambiental (enriquecimento ambiental) e táctil (Levitsky e Barnes, 1972; Gomes et al, 1999; Lima et al, 1999; Riul et al, 1999). O enriquecimento ambiental pode aumentar a exploração nos braços abertos no labirinto em cruz elevado (Santucci et al, 1994), além de alterar níveis de alguns neurotransmissores, como o glutamato (Wood et al, 2005), influenciando processos bioquímicos no cérebro do animal com déficit nutricional (Lima et al, 1999).

A estimulação ambiental pode resultar, em ratos, no aumento do comportamento exploratório (Levitsky e Barnes, 1972) e atenuar déficits cognitivos preservando a integridade tecidual após danos cerebrais em ratos (Passineau, Green e Dietrich, 2001). Estudos mostraram que ratos expostos à estimulação ambiental apresentam um maior tempo de exploração dos braços abertos do labirinto em cruz elevado (Fernandez-Teruel et al, 1990; Mcintosh et al, 1999), e aumento de exploração no campo aberto (Fernandez-Teruel et al, 1997).

Já a estimulação táctil (handling) tem participação fundamental na modulação de respostas comportamentais, como no desenvolvimento do sistema sensório-motor (Cancedda et al, 2004) e pode amenizar possíveis perdas provocadas pela desnutrição em algumas estruturas do sistema nervoso central (Gomes et al, 1999).

Tem sido descrito períodos críticos do desenvolvimento cerebral durante a gestação e logo após o nascimento, nos quais o cérebro é mais sensível a estímulos ambientais (Tejedor-Real et al, 1998). Durante o período de crescimento mais acelerado do organismo o 
desenvolvimento de estruturas do SNC é influenciado diretamente pelas condições ambientais (Chapillon et al 2002). De acordo com Meaney e Aitken (1985) a estimulação neonatal tem um maior efeito até os 14 primeiros dias após o nascimento, sendo a estimulação mais efetiva na primeira semana. Nesta primeira semana as experiências ambientais, como a estimulação táctil (handling), por exemplo, podem alterar a sensibilidade do eixo hipotálamo-hipófiseadrenal (HPA) (Gomes et al, 1999; Jutapakdeegul et al, 2003).

A estimulação neonatal pode levar à diminuição dos níveis de $\mathrm{ACTH}$, do conteúdo do hormônio liberador de corticotrofina $(\mathrm{CRH})$ na eminência mediana e de corticosterona plasmática em resposta ao estresse agudo (Pryce e Feldon, 2003). Há também um aumento na densidade dos receptores glicocorticóides no hipocampo, o que resulta na melhor retroalimentação negativa no eixo HPA, exercida pelos glicocorticóides (Smythe et al, 1994, Liu et al, 1997; Gomes et al, 1999; Wigger e Neumann, 1999). Schanberg e Field (1987) mostraram que a estimulação táctil em ratos aumentou os níveis do hormônio do crescimento e da ODC.

As estimulações, ambiental e táctil, também podem influenciar os receptores de glutamato que são divididos em 2 grupos: metabotrópicos e ionotrópicos. Os receptores metabotrópicos alteram os processos intracelulares através de mecanismos de transdução de sinal e esta via interfere em uma ampla variedade de funções celulares. Os receptores ionotrópicos causam influxo dos íons através da membrana celular e mudanças no potencial de membrana durante o desenvolvimento do SNC (Levitsky e Barnes, 1972). Os receptores de glutamato participam na regulação do crescimento axonal e dendrítico e da sinaptogênese (Mattson et al, 1988; Diamond, 2001).

De acordo com alguns estudos (Cancedda et al, 2004; Artola et al, 2006) a estimulação ambiental e táctil pode desempenhar um papel importante na plasticidade cerebral, possibilitando que o sujeito apresente melhoria na aprendizagem. 
Krech, Rosenzweig e Bennett (1960), já na década de 60, mostraram que roedores expostos ao ambiente enriquecido podem ter algumas estruturas e funções do encéfalo alteradas. Muitos trabalhos têm mostrado que o córtex cerebral, de animais expostos ao ambiente enriquecido, apresenta uma maior espessura, principalmente no córtex occipital, em comparação com animais que vivem em condições padrões de laboratório (Rosenzweig et al, 1968; Rosenzweig e Bennett 1996; Lima et al, 1999). Uma das razões para o aumento do córtex pode ser o aumento do tamanho dos neurônios, o número e o comprimento dos dendritos e o aumento de espinhas dendríticas (Diamond et al, 1964).

O enriquecimento ambiental pode atenuar os déficits causados por injurias no SNC de ratos (Will et al 2004). Entre as lesões que se podem impor ao rato, uma bastante utilizada é a hipóxia-isquêmica, que pode resultar em lesões cerebrais no hipocampo e em outras estruturas do SNC, com déficit de memória e do aprendizado espacial (Netto et al, 1993). Rodrigues e colaboradores (2005) observaram que a estimulação táctil e enriquecimento ambiental possibilitam a recuperação do dano causado no hipocampo em animais que sofreram hipóxia, além de reverter o prejuízo no aprendizado espacial. Também foram mostradas evidências de que a estimulação ambiental pode colaborar na recuperação após o evento isquêmico, aumentando o número de neurônios e a densidade de espinhas sinápticas no giro denteado (Briones et al, 2004).

De acordo com Phan e colaboradores (1997) e Wood e colaboradores (2005) os efeitos da estimulação ambiental podem persistir durante a maturidade. Ratos senescentes são caracterizados, entre outros aspectos, pela perda de neurônios no hipocampo e aumento dos níveis de costicosterona plasmática e diminuição dos receptores glutamatérgicos (Salpolsky et al, 1985). Pode-se dizer que a estimulação neonatal previne a perda neuronal associada à idade (Phan et al, 1997). Em um estudo usando o enriquecimento ambiental (Globbo e 
O’Mara, 2004), mostrou-se que o BDNF teve seus níveis aumentados comparados com ratos que viveram em condições padrão.

Para o estudo de efeitos comportamentais e outras variáveis, é comum a utilização de modelos animais. Dentre os vários modelos animais de ansiedade, um dos mais utilizados é o teste do labirinto em cruz elevado, que foi desenvolvido por Handley e Mithani (1984), baseado no estudo de Montgomery em 1955. Para o estudo de ansiedade no LCE foram validadas as seguintes medidas: porcentagem de entradas nos braços abertos e fechados, porcentagem de tempo gastos nestes braços e número de entradas nos braços fechados.

As medidas que estariam relacionadas diretamente à ansiedade seriam aquelas avaliadas nos braços abertos. (Pellow et al, 1985; Lister, 1987). Também foram validados outros comportamentos exploratórios em ratos e camundongos, tais como levantamento, congelamento, autolimpeza, esticamentos e mergulhos (Blanchard et al 1991; Rodgers et al, 1997).

O LCE tem a propriedade de avaliar, além de respostas relacionadas com a ansiedade, também a atividade locomotora dos roedores (Holmes e Rodgers, 1994), sendo o número de entradas nos braços fechados o melhor indicador de locomoção. No entanto é importante ressaltar que uma única exposição ao LCE pode alterar o comportamento de ratos (Cruz et al, 1991; Rodgers et al, 1997). Alguns estudos mostraram que ratos reexpostos (expostos por duas vezes) ao LCE tiveram uma menor percentagem no número de entradas e de tempo de permanência nos braços abertos, quando estes são comparados aos animais expostos pela primeira vez ao LCE (Rodgers e Shepherd, 1993; Bertoglio e Carobrez, 2000).

Ressalta-se a importância de se investigar mais profundamente os efeitos da desnutrição no organismo, bem como seus possíveis efeitos comportamentais e bioquímicos, assim como estudar maneiras de atenuar ou até mesmo reverter danos causados pela desnutrição proteica. $\mathrm{Na}$ literatura não há dados sobre os efeitos comportamentais e sobre os níveis de 
corticosterona plasmática e de poliaminas, ao mesmo tempo comparando a estimulação táctil (handling), com a estimulação ambiental (enriquecimento ambiental), em ratos desnutridos ou não, no período de desenvolvimento do SNC (de 8 a 35 dias de idade). 


\section{OBJETIVOS}

\subsection{Objetivo principal}

- Investigar os efeitos da desnutrição protéica precoce e da estimulação ambiental sobre medidas bioquímicas e comportamentais em ratos.

\subsection{Objetivos específicos}

- Investigar os efeitos bioquímicos e comportamentais produzidos pelo handling e pelo ambiente enriquecido durante a fase de desenvolvimento do SNC;

- Investigar os efeitos da desnutrição protéica e da estimulação ambiental sobre os níveis de poliaminas no hipocampo e no córtex occipital e níveis de corticosterona plasmática;

- Investigar os efeitos da estimulação ambiental sobre a recuperação dos prejuízos causados pela desnutrição protéica precoce em medidas bioquímicas e comportamentais. 


\section{MATERIAL E MÉTODO}

\subsection{Sujeitos}

No presente estudo foram utilizadas ratas, Wistar, adultas, com cerca de 70 dias de idade, provenientes do biotério central do Campus da USP de Ribeirão Preto, e transportadas para o Laboratório de Pesquisas em Nutrição, Desenvolvimento e Comportamento. As ratas foram mantidas em grupos de 3 por gaiola durante um período de 1 semana (adaptação). Após esse período foram colocadas para acasalamento (3 fêmeas para cada macho) e acompanhadas durante a gestação, até o dia do parto, sempre mantidas com ração comercial e água ad libitum.

No dia do nascimento foram compostas as ninhadas com 6 filhotes machos e 2 fêmeas, totalizando 8 filhotes para cada rata mãe. As ninhadas foram compostas a partir de um conjunto maior de ratos. As ninhadas nascidas num mesmo dia foram colocadas juntas e os ratos foram escolhidos randomicamente para a composição das ninhadas experimentais. No início da lactação foram compostos os grupos de animais Controles (C - dieta com 16 \%) e Desnutridos (D - dietas com 6\% de proteína). As dietas foram preparadas no próprio laboratório e oferecidas aos animais até os 35 dias de idade.

Os animais (mães e ninhadas) foram pesados nos dias 01, 07, 14, e 21 do período de lactação. Após o desmame os filhotes foram pesados individualmente aos 28 e 35 dias de idade. Após o período de lactação as mães e os filhotes fêmeas foram descartados e os filhotes-machos foram separados de suas mães e colocados individualmente em gaiolasviveiro. 


\subsubsection{Composição dos grupos}

Os animais foram divididos em 2 grandes grupos: Desnutridos - D (6\% de proteína), que foram mantidos com dietas com a seguinte composição: Proteína - 6\%; carboidrato (maisena) - 79.8\%; lipídeos (óleo de milho) - 8\%; mistura salina - 5\%; mistura de vitamina 1\%; colina $0.2 \%$; além de metionina ( $2 \mathrm{~g}$ por quilo total de caseína). O grupo Controle - C (16\% de proteína), com as dietas contendo a seguinte composição: Proteína - 16\%; carboidrato (maisena) - 69.8\%; lipídeos (óleo de milho) - 8\%, mistura salina - 5\%; mistura de vitamina $1 \%$; colina $0.2 \%$; alem de metionina ( 2 g por quilo total de caseína).

Os animais de ambos os grupos foram submetidos a diferentes manipulações ambientais, e conseqüentemente subdivididos de acordo com tais manipulações: Enriquecimento Ambiental (E), Estimulação Táctil (H) e Não estimulação (N).

Para analisar os efeitos da estimulação algumas ninhadas foram expostas ao Enriquecimento Ambiental ou a Estimulação Táctil (Handling) durante o período de 8 a 35 dias de idade (Tabela 1). A estimulação (handling e enriquecimento ambiental) foi iniciada no $8^{\circ}$ dia com o proposto de comparar os dados do presente estudo com aqueles obtidos por Pereira e colaboradores (2006 e 2008).

Tabela 1: Grupos experimentais conforme a sua condição de dieta e estimulação. Estimulação Táctil $\left(\mathrm{H}_{1}\right.$ e $\left.\mathrm{H}_{2}\right)$ e Enriquecimento Ambiental $\left(\mathrm{E}_{1}\right.$ e $\left.\mathrm{E}_{2}\right)$ e seus respectivos períodos, em cada grupo experimental. A manipulação ambiental foi realizada durante a lactação de 8 a 21 dias, e durante a fase de pós-lactação, de 22 a 35 dias. $\mathrm{N}$ representa período em que não houve estimulação, E representa o enriquecimento ambiental e H o handling. (n = 8 animais por grupo)

\begin{tabular}{c|c|c|c|c|c}
\hline Período & \multicolumn{2}{|c|}{$8-21$ dias } & \multicolumn{2}{|c|}{$21-35$ dias } & \\
\hline Estimulação & $\mathrm{E}_{1}$ & $\mathrm{H}_{1}$ & $\mathrm{E}_{2}$ & $\mathrm{H}_{2}$ & Grupos \\
\hline Controle & $\mathrm{N}$ & $\mathrm{N}$ & $\mathrm{N}$ & $\mathrm{N}$ & CNN \\
$(\mathrm{C})$ & $\mathrm{E}$ & $\mathrm{N}$ & $\mathrm{E}$ & $\mathrm{N}$ & CEE \\
& $\mathrm{N}$ & $\mathrm{H}$ & $\mathrm{N}$ & $\mathrm{H}$ & CHH \\
\hline Desnutridos & $\mathrm{N}$ & $\mathrm{N}$ & $\mathrm{N}$ & $\mathrm{N}$ & MNN \\
$(\mathrm{M})$ & $\mathrm{E}$ & $\mathrm{N}$ & $\mathrm{E}$ & $\mathrm{N}$ & MEE \\
& $\mathrm{N}$ & $\mathrm{H}$ & $\mathrm{N}$ & $\mathrm{H}$ & MHH \\
\hline
\end{tabular}




\subsection{Equipamento}

No período de lactação ( 0 a 21 dias de idade), os grupos não estimulados foram mantidos em gaiolas medindo $40 \times 25 \times 20 \mathrm{~cm}$, com 3 lados de material acrílico fosco, parede da frente em aço inoxidável com e um túnel para alimentação $(5$ x $9 \mathrm{~cm})$ e piso de aço para colocação de raspas de madeira (maravalha).

Para os grupos estimulados, durante o período de lactação, foram utilizadas gaiolas com as mesmas dimensões e características descritas para as gaiolas do grupo não-estimulado, diferenciando-se daquelas no que diz respeito às paredes laterais em acrílico transparente. Nesta mesma gaiola havia a presença de objetos, como rodas de atividade, túneis, brinquedos de plástico (com formatos e texturas diferentes), bolinhas de gude, objetos que emitiam sons (como chocalhos), espelhos e pedaços de madeira. Todos estes objetos eram trocados semanalmente, a fim de garantir o efeito novidade, como descrito em Diamond (2001).

A Gaiola de Ambiente Enriquecido ( $\left.\mathrm{E}_{2}\right)$, utilizada no período de pós-lactação, consistia em uma gaiola de medidas 40 × 60 × $90 \mathrm{~cm}$ com três pavimentos interligados por rampas contendo uma roda de atividade e diversos outros objetos (brinquedos de plásticos, bolas de borrachas, objetos de madeira) com formas, texturas e cores diferentes, e ainda objetos que, ao serem tocados pelos animais, podiam emitir som (Diamond, 2001; Pereira et al, 2006 e 2008), além de espelhos nas paredes laterais. Tais objetos como no Ambiente Enriquecido 1 $\left(E_{1}\right)$ foram trocados semanalmente, para também garantir o efeito novidade.

Para o teste do Labirinto em Cruz Elevado (LCE), foi utilizado um equipamento de madeira, elevado a uma altura de $50 \mathrm{~cm}$ do solo, constituído de dois braços abertos (50x10 $\mathrm{cm}$ ) com uma borda de acrílico de 1,0 cm, dois braços fechados com as paredes de madeira $(50 \times 10 \times 40 \mathrm{~cm})$, unidos ortogonalmente a uma plataforma central $(10 \times 10 \mathrm{~cm})$.

Neste teste o rato era colocado no centro do aparato com a cabeça voltada para os braços fechados, e permitido explorar o aparato por cinco minutos. Os animais foram por duas vezes 
expostos ao aparato em dias sucessivos (aos 36 e 37 dias de idade). Após 24 horas da $1^{\text {a }}$ Exposição, foi realizada a $2^{\mathrm{a}}$ Exposição ao LCE, com o procedimento semelhante ao da $1^{\mathrm{a}}$ Exposição.

As sessões no LCE foram registradas em vídeo-câmera para uma posterior análise dos seguintes comportamentos: freqüência de entradas nos braços abertos e fechados (entrada no braço definida pela colocação das quatro patas dentro do braço), tempo de permanência em ambos os braços e no centro, além de suas respectivas porcentagens; exploração vertical (rearing); mergulhos protegidos (quando realizados nos braços fechados e no centro) e desprotegidos (quando realizados nos braços abertos), considerando-se mergulho quando o animal se apóia nas patas traseiras e inclina a cabeça para fora do braço aberto em direção ao piso da sala onde está instalado o labirinto; esticamento protegidos (quando realizados nos braços fechados e no centro) e desprotegidos (quando realizados nos braços abertos), considerando-se esticamento quando o animal mantém as patas traseiras imóveis e estica o corpo para a frente, seguido da volta para a mesma posição.

\subsection{Procedimentos}

\subsubsection{Estimulação táctil (Handling)}

Durante o período de 8 a 21 dias os grupos de animais do grupo controle submetido ao handling $(\mathrm{CHH})$ e desnutrido submetido ao handling $(\mathrm{MHH})$ (Tabela 1) foram retirados de suas caixas-viveiro, nas quais viviam em uma ninhada composta da rata-mãe e de 8 filhotes, e foram individualmente submetidos à Estimulação Táctil (Handling) durante 3 minutos.

A Estimulação Táctil (Handling) consistia em segurar o animal com umas das mãos, enquanto que o polegar da outra mão do experimentador deslizava no dorso do animal no sentido cabeça-cauda. Ao término do manuseio animais eram agrupados em suas ninhadas, 
sem a rata-mãe, e levados na gaiola de lactação a uma outra sala, onde foram expostos à estimulação sonora (70 Db e $3 \mathrm{KHz}$ ) durante 3 minutos (3 segundos de som continuo e intervalos de 25 segundos entre tons), conforme o protocolo experimental previamente estabelecido no laboratório (Santucci et al, 1994 e Feliciano, 2007).

Os grupos controle e não-estimulado $(\mathrm{CNN})$ e desnutrido e não-estimulado ( $\mathrm{MNN}$ ) (Tabela1), que são grupos que não passaram pela estimulação táctil durante o período de 8 a 21 dias, foram mantidos em sua gaiola de lactação, mas separados de suas ratas-mães durante um mesmo período de manipulação dos grupos estimulados.

No período de 22 a 35 dias de vida os animais já estavam alojados em gaiolas individuais, e para a realização da estimulação tátil foram retirados de suas gaiolas. Após esta estimulação táctil eram colocados em gaiolas coletivas, com os outros animais pertencentes ao mesmo grupo. Após a exposição à estimulação sonora esses animais retornavam para a gaiola individual.

\subsubsection{Ambiente Enriquecido}

No primeiro procedimento, denominado Enriquecimento Ambiental $1\left(\mathrm{E}_{1}\right)$, os grupos controles submetidos ao enriquecimento ambiental (CEE) e desnutridos submetidos ao enriquecimento ambiental (MEE) (Tabela 1), do $8^{\circ}$ ao $21^{\circ}$ dia de vida, foram expostos a uma caixa-viveiro (descrita em equipamentos) por um período de 1 hora.

No período de pós-lactação $\left(22^{\circ}\right.$ ao $35^{\circ}$ dia de vida) o Enriquecimento Ambiental $2\left(\mathrm{E}_{2}\right)$ ocorreu por 14 dias, também sendo realizado durante 1 hora por dia. Neste processo, os grupos CEE e MEE, foram colocados em uma gaiola especial (descrita em equipamentos), para livre exploração, sempre mantendo um misto de pelo menos três ninhadas diferentes (entre 8 e 16 animais por sessão), para garantir a interação social entre animais provenientes de diferentes ninhadas (Pereira et al, 2006 e 2008). 
Como já descrito anteriormente, os grupos CNN e MNN (Tabela1), que são grupos que não passaram pelo enriquecimento ambiental, durante o período de 8 a 21 dias, foram mantidos em sua gaiola de lactação, mas separados de suas ratas-mães durante um mesmo período de manipulação dos grupos estimulados.

\subsection{Análises Bioquímicas.}

No $37^{\circ}$ dia de vida, após a $2^{\mathrm{a}}$ sessão do teste no LCE, entre as $08 \mathrm{~h} 00 \mathrm{~min}$ e $09 \mathrm{~h} 30 \mathrm{~min}$, os ratos foram sacrificados, decapitados e tiveram os seus cérebros removidos e o sangue coletado para as dosagens bioquímicas.

\subsubsection{Corticosterona plasmática}

As dosagens de corticosterona plasmática foram realizadas no Laboratório de Fisiologia da Faculdade de Medicina de Ribeirão Preto - Universidade de São Paulo, sob a orientação do Prof. Dr. José Antunes Rodrigues e da Profa. Dra Lucila Leico Kagohara Elias.

Após a retirada do sangue os tubos contendo o material foram centrifugados a $25^{\circ} \mathrm{C}$ e a $5000 \mathrm{rpm}$, e o sobrenadante foi retirado e congelado a $-70^{\circ} \mathrm{C}$. No dia da dosagem os tubos foram descongelados em temperatura ambiente e, logo após, iniciou-se o procedimento para a determinação da corticosterona plasmática.

A corticosterona plasmática foi determinada pelo método de Vecsei e colaboradores (1979), que utiliza extração do esteróide com etanol. Foi utilizado um anticorpo anticorticosterona (AB-cort-17984) preparado em coelhos, com o hormônio conjugado com albumina bovina. A corticosterona $[1,2-3(\mathrm{H})]$ (New England Nuclear) foi utilizada como hormônio marcado. Na separação da fração livre da ligada foi utilizada uma solução de carvão-dextran 0,5/0,05\% A dose mínima detectável e os coeficientes de variação intra e inter-ensaio foram 0,4 $\mu \mathrm{g} / \mathrm{dL}, 5,1 \%$ e 8,4\%, respectivamente (Elias et al 1997 e 2004). 


\subsubsection{Poliaminas}

As dosagens de Poliaminas (hipocampo e córtex occipital) foram realizadas no Laboratório de Nutrição do Departamento de Clinica Médica da Faculdade de Medicina de Ribeirão Preto - Universidade de São Paulo. Os métodos para a dosagem em cromatografia de alto desempenho (high performance liquid chromatography - HPLC) foram desenvolvidos com orientação do Prof. Dr. Sergio Marchini, a partir do método descrito por Löser, Wunderlich e Fölsh (1988).

Após a extração do hipocampo e córtex occipital, as amostras foram congeladas a $-70^{\circ} \mathrm{C}$. No dia da analise, após o descongelamento das amostras a temperatura ambiente, foi adicionada uma solução salina a $0,9 \%$ no ependorf contendo a amostra a uma proporção de 1:20 (peso (g)/volume (ml)) e, logo em seguida, realizada a homogeneização com o uso de um sonicador (Ultrassonic Processor Modelo GE 130PB) por 4 vezes durante 5 segundos cada vez. Ao homogeneizado foi colocado $50 \mu \mathrm{l}$ de padrão interno (1,7-diaminoheptano, 300 $\mathrm{nMol} / \mathrm{ml}$ ) e $700 \mu 1$ de Acido Perclórico (PCA) a 70\% 0,2 molar. Logo após a amostra foi centrifugada a $3200 \mathrm{~g}$ por 5 minutos e o sobrenadante passado por filtro Millex de 0,22 $\mu \mathrm{m}$ e $20 \mu \mathrm{l}$ foi injetado no HPLC.

A mistura de Padrões (putrescina, espermina, espermidina e padrão interno) para a calibração do HPLC continha em um volume de $\mu 1$ injetado, 27,08 pMol de putrescina, 205,6 pMol de espermina, 305,76 pMol de espermidina e 176,92 pMol de padrão Interno. A concentração das poliaminas nos tecidos foi expressa em $\mathrm{pMol} / \mathrm{g}$ de tecido.

Para as análises bioquímicas de poliaminas foi utilizado uma cromatográfico liquido de alta pressão (HPLC) da marca Shimadzu Cosporation modelo LC-10Ad, equipado com duas bombas de alta pressão modelo Shimadzu LC-10AD, uma bomba para mistura de gradientes Shimadzu CBM-10 A, auto-sampler Shimadzu SIL-10 A e um forno modelo Shimadzu CTO10 A para aquecimento da coluna a $37^{\circ} \mathrm{C}$. Para a separação das poliaminas foi usada uma 
coluna contendo fase ligada de octadecisiliano (C18) da marca LiChrospher ${ }^{\circledR} 100 \mathrm{RP} 18$ da Merck-Germany com fluxo de $0,45 \mathrm{~mL} / \mathrm{min}$.

\subsection{Análise Estatística}

Os dados de peso corporal (das mães e dos filhotes), assim como as medidas bioquímicas e comportamentais foram inicialmente avaliadas quanto à normalidade da distribuição. Os dados de peso corporal foram submetidos à análise de variância (ANOVA) de três fatores (dieta, dia de vida e estimulação). Os dados comportamentais foram submetidos a uma ANOVA de três fatores (dieta, estimulação e teste) com repetição no fator teste. Os dados bioquímicos foram submetidos a uma ANOVA de dois fatores (dieta e estimulação). Quando apropriado foi realizado teste de comparações múltiplas (Newman-Keuls), considerado significativo o valor de $\mathrm{p}<0,05$. 


\section{RESULTADOS}

\subsection{Peso corporal}

No que se refere ao peso corporal das ratas-mães a ANOVA mostrou diferenças estatisticamente significativas para o fator dieta $\left(\mathrm{F}_{(1,14)}=101,40 ; \mathrm{p}<0,001\right)$ e para $\mathrm{o}$ fator dia $\left(\mathrm{F}_{(3,42)}=51,13 ; \mathrm{p}<0,001\right)$. Entretanto, não houve diferença significativa para $\mathrm{o}$ fator estimulação $\left(\mathrm{F}_{(2,14)}=1,76 ; \mathrm{p}>0,05\right)$. Também houve diferença significativa na interação entre os fatores dieta e dia $\left(\mathrm{F}_{(3,42)}=26,62 ; \mathrm{p}<0,001\right)$ e entre os fatores estimulação e dia $\left(\mathrm{F}_{(6,42)}=\right.$ $2,51 ; \mathrm{p}<0,05)$.

Como demonstrado na Figura 1 é possível observar que houve uma queda do peso das ratas-mães a partir do dia 7 da lactação, sendo que esta queda se manteve para os outros dias (14 e 21), enquanto que nas ratas controle não houve variação do peso-corporal ao longo da fase de lactação. Também é evidente o menor peso das ratas-mães desnutridas quando comparado ao peso das ratas controle a partir do dia 14 .

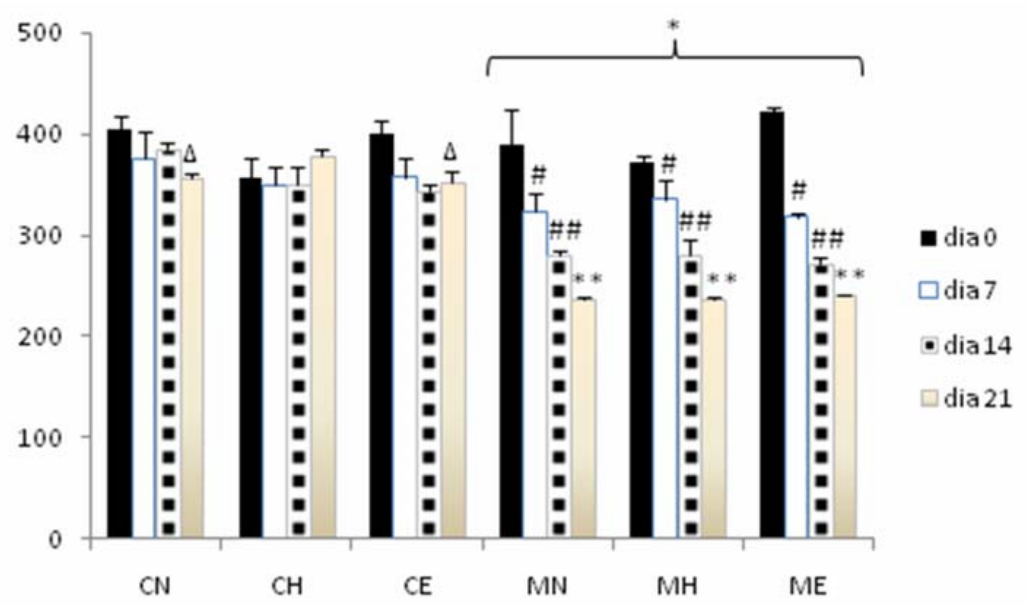

Figura 1: Pesos das ratas-mães nos dias 0, 7, 14 e 21 cujas ninhadas foram designadas como controle não estimulado $(\mathrm{CN})$; controle submetido ao handling $(\mathrm{CH})$; controle submetido ao ambiente enriquecido (CE); desnutrido não estimulado (DN); desnutrido submetido ao handling (DH) e desnutrido submetido ao ambiente enriquecido (DE). ${ }^{*} \mathrm{p}<0,05$ comparado ao desnutrido, \# $\mathrm{p}<0,05$ comparado com o dia $0, \# \# \mathrm{p}<0,05$ com os dias 0 e $7 ; * * \mathrm{p}<0,05$ com os demais dias; e $\Delta \mathrm{p}<0,05$ com o dia 0 . 
Com relação ao peso corporal das ninhadas durante o período de lactação, encontrou-se diferença significativa para o fator dieta $\left(F_{(1,18)}=752,84 ; p<0,001\right)$, para o fator estimulação $\left(F_{(2,18)}=4,66 ; p<0,01\right)$ e para o fator dia $\left(F_{(3,54)}=628,78 ; p<0,001\right)$. Também houve diferença significativa na interação entre os fatores dieta e estimulação $\left(F_{(2,18)}=27,87 ; p<0,001\right)$, dieta e dia $\left(\mathrm{F}_{(3,54)}=215,94 ; \mathrm{p}<0,001\right)$, estimulação e dia $\left(\mathrm{F}_{(6,54)}=4,27 \mathrm{p}<0,01\right)$ e entre os três fatores, dieta, estimulação e dia $\left(\mathrm{F}_{(6,54)}=15,17 ; \mathrm{p}<0,001\right)$.

A análise post-hoc mostrou que as ninhadas pertencentes aos grupos controle tiveram um maior peso corporal a partir do dia 7, quando comparadas aos grupos desnutridos (Figura 2). Houve também uma diferença em relação aos animais estimulados na mesma condição de dieta. Animais controle não-estimulados $(\mathrm{CN})$ apresentaram um maior peso-corporal quando comparado aos animais submetidos ao handling $(\mathrm{CH})$ e animais submetidos ao enriquecimento ambiental (CE), tanto no dia 7 como no dia 14. No dia 21 os animais do grupo CN apresentaram peso corporal maior apenas em relação aos animais do grupo CE, já o grupo $\mathrm{CH}$ apresentou peso corporal significante maior quando comparados aos demais grupos controle. Com relação aos animais desnutridos é importante ressaltar que os animais do grupo controle submetidos ao enriquecimento ambiental (CE), no dia 21, apresentaram maior peso corporal quando comparados com os animais demais grupos desnutridos.

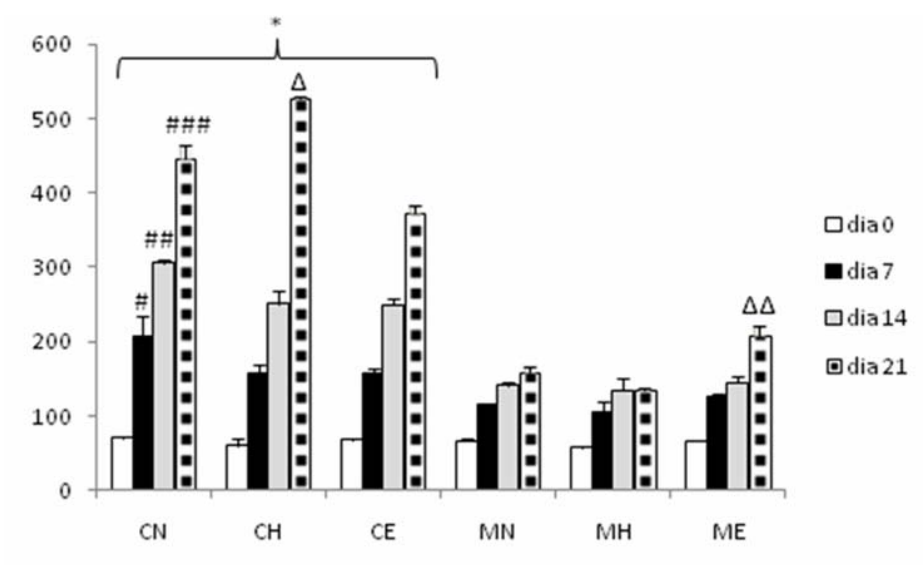

Figura 2: Médias de pesos das ninhadas nos período de lactação (0 a 21 dias). Controle não estimulado $(\mathrm{CN})$; controle submetido ao handling $(\mathrm{CH})$; controle submetido ao ambiente enriquecido (CE); desnutrido não estimulado (DN); desnutrido submetido ao handling (DH) e desnutrido submetido ao ambiente enriquecido (DE). Estatisticamente significante *p<0,05 com relação a desnutrido (dia7, 14 e 21) e \# p<0,05com relação a $\mathrm{CH}$ e CE; \#\# $\mathrm{p}<0,05$ com relação a $\mathrm{CH}$ e $\mathrm{CE}$; \#\# $\mathrm{p}<0,05$ com relação a $\mathrm{CE} ; \Delta \mathrm{p}<0,05$ com relação a $\mathrm{CE} ; \Delta \Delta$ $\mathrm{p}<0,05$ com relação a $\mathrm{MN}$ e $\mathrm{MH}$. 
A análise do peso corporal dos sujeitos nos 28 e 35 dias de vida mostrou que há diferenças significativas para os fatores dieta $\left(F_{(1,88)}=1734,34 ; p<0,001\right)$, e dia $\left(F_{(1,88)}=301,86 ; p<0,001\right)$, no entanto a ANOVA não mostrou diferença significativa para o fator estimulação $\left(\mathrm{F}_{(2,88)}=\right.$ $1,64 ; p>0,05)$. Houve diferenças significativas para as interações entre os fatores dieta e dia $\left(\mathrm{F}_{(1,88)}=222,26 ; \mathrm{p}<0,001\right)$ e estimulação e dia $\left(\mathrm{F}_{(2,88)}=4,18 ; \mathrm{p}<0,05\right)$.

A Figura 3 mostra que os animais pertencentes aos grupos controle apresentam um maior peso corporal quando comparado com os animais desnutridos. Também é possível observar o aumento de peso de animais controle no dia 35 quando comparado com o dia 28, o que não foi observado no grupo desnutrido.

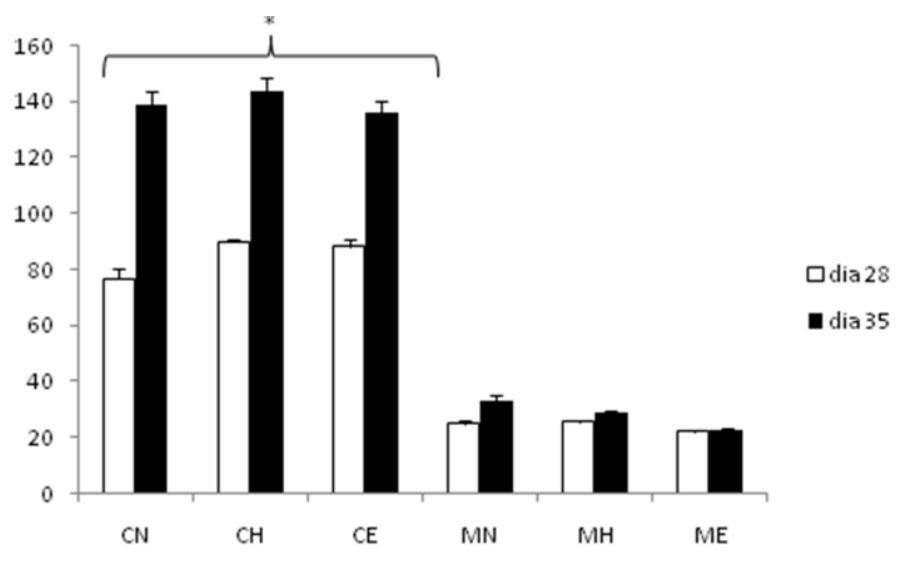

Figura 3: Médias de pesos dos ratos nos período de pós-lactação (28 e 35 dias). Controle não estimulado $(\mathrm{CN})$; controle submetido ao handling $(\mathrm{CH})$; controle submetido ao ambiente enriquecido (CE); desnutrido não estimulado (DN); desnutrido submetido ao handling (DH) e desnutrido submetido ao ambiente enriquecido (DE). ${ }^{*} \mathrm{p}<0,05$ comparado ao desnutrido.

\subsection{Labirinto em cruz elevado}

Com relação à porcentagem do número de entradas nos braços abertos (EBA), a ANOVA mostrou diferenças significativas para os fatores dieta $\left(F_{(1,41)}=26,67 ; p<0,001\right)$ e reexposição ao $\operatorname{LCE}\left(\mathrm{F}_{(1,41)}=8,04 ; \mathrm{p}<0,01\right)$, no entanto, não mostrou diferença significativa para o fator estimulação $\left(\mathrm{F}_{(2,41)}=0,23 ; \mathrm{p}>0,05\right)$. A ANOVA também mostrou diferença significativa para a interação entre a estimulação e a reexposição ao aparato $\left(\mathrm{F}_{(2,41)}=14,90 ; \mathrm{p}<0,001\right)$. 
A Figura 4 mostra que os grupos CNN e MNN possuem uma percentagem de EBA $(2,4 \%$ e $21 \%$ ), estatisticamente menor $(\mathrm{p}<0,05)$ na $2^{\mathrm{a}}$ exposição ao LCE, quando comparada com as porcentagens dos próprios grupos CNN (14\%) e MNN (30\%) na primeira exposição.

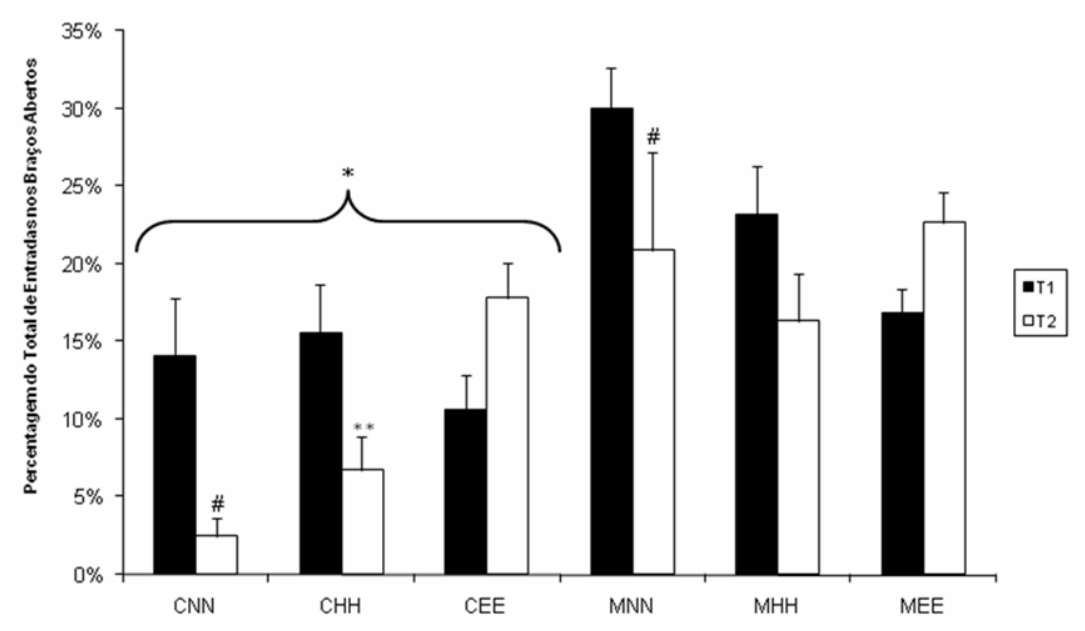

Figura 4: Percentagem do total de Entradas nos braços abertos. Grupos que submetidos à estimulação durante o período de 8 a 35 dias. Sendo T1 e T2, referentes a $1^{\mathrm{a}}$ e $2^{\mathrm{a}}$ exposição ao LCE, respectivamente. ${ }^{*} \mathrm{p}<0,05$ com relação ao desnutrido; ** $\mathrm{p}<0,05$ com relação ao CNN e CEE; e \# $\mathrm{p}<0,05$ com relação a T1.

A análise estatística da porcentagem do tempo de permanência nos braços abertos (TBA) mostrou que há diferenças significativas para os fatores dieta $\left(\mathrm{F}_{(1,41)}=18,35 ; \mathrm{p}<0,001\right)$ e reexposição $\left(\mathrm{F}_{(1,41)}=20,64 ; \mathrm{p}<0,001\right)$, mas não para o fator estimulação $\left(\mathrm{F}_{(2,41)}=0,97\right.$; $p>0,05)$. Também houve interação entre os fatores estimulação e reexposição $\left(F_{(2,41)}=12,21\right.$; $\mathrm{p}<0,001)$.

O grupo MNN na primeira exposição ao LCE possui uma maior porcentagem de TBA $(\mathrm{p}>0,05)$ quando comparado com os demais grupos (Figura 5). Os grupos CNN e MNN apresentam maiores porcentagens de TBA na primeira exposição quando comparadas à segunda exposição ao aparato $(\mathrm{p}<0,05)$. 


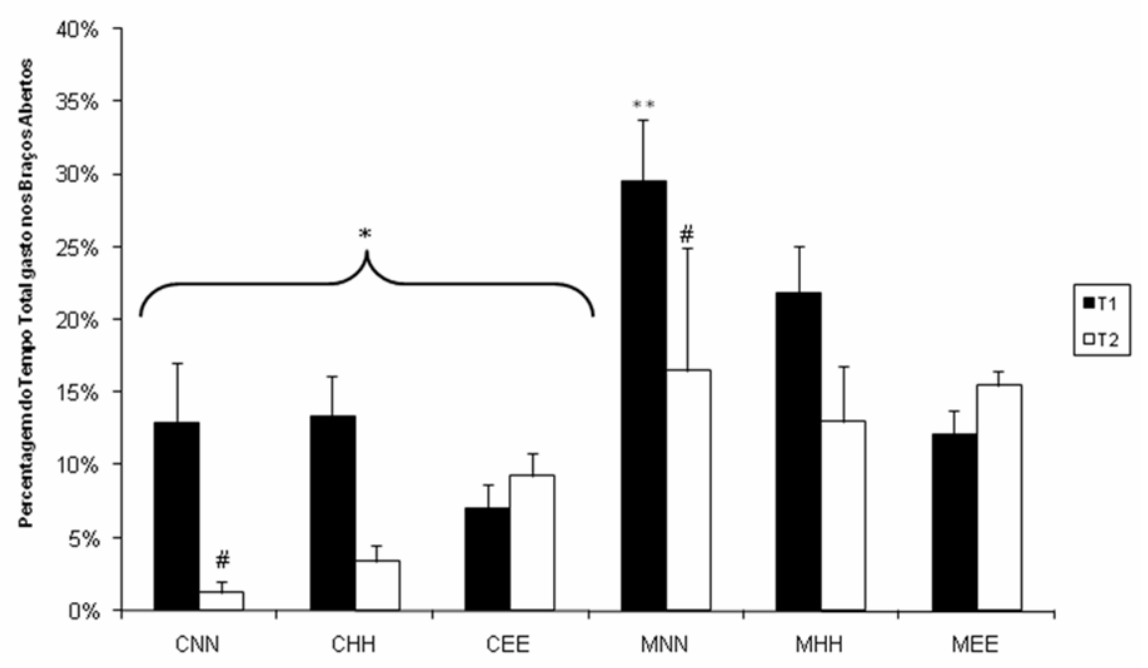

Figura 5: Porcentagem do tempo de permanecia nos braços abertos. Grupos que submetidos à estimulação durante o período de 8 a 35 dias. Sendo T1 e T2 referentes a $1^{\mathrm{a}}$ e $2^{\mathrm{a}}$ exposição ao LCE, respectivamente. * $\mathrm{p}<0,05$ com relação ao desnutridos; ** $\mathrm{p}<0,05$ com relação a todos os outros grupos; $\mathrm{e}$ \# $\mathrm{p}<0,05$ com relação a T1.

Com relação ao numero de entradas nos braços fechados (EBF) houve diferenças significativas para os fatores dieta $\left(\mathrm{F}_{(1,41)}=10,48 ; \mathrm{p}<0,01\right)$, estimulação $\left(\mathrm{F}_{(2,41)}=8,50\right.$; $\mathrm{p}<0,001)$ e reexposição ao aparato $\left(\mathrm{F}_{(1,41)}=4,67 ; \mathrm{p}<0,05\right)$. Também que houve interação dos fatores estimulação e reexposição $\left(\mathrm{F}_{(2,41)}=4,53 ; \mathrm{p}<0,01\right)$.

Na Figura 6 é possível observar que os animais submetidos à desnutrição entraram menos nos braços fechados quando comparados com animais controle $(\mathrm{p}<0,05)$. Também é possível observar que o grupo CEE apresenta um maior número de EBF na segunda exposição ao LCE $(55,6)$ quando comparado com os animais $\mathrm{CNN}(35,0)(\mathrm{p}<0,05)$. O grupo CEE apresentou um maior numero de EBF na primeira exposição $(65,88)$ quando comparado com a segunda exposição $(55,63)$ ao aparato $(\mathrm{p}<0,05)$. 


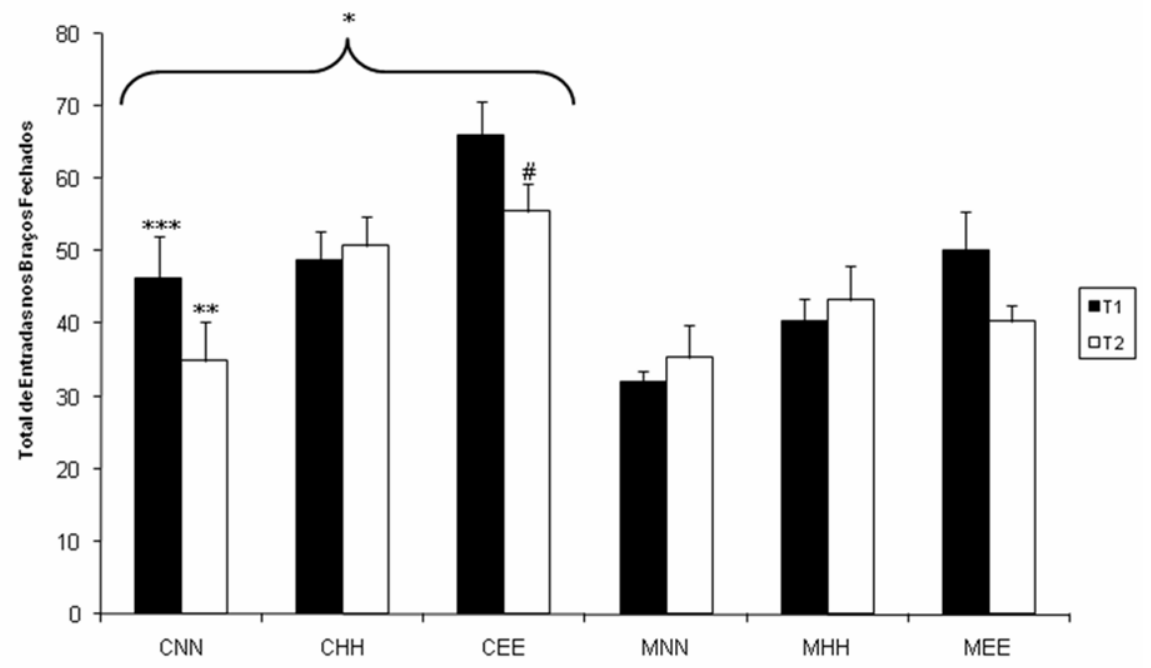

Figura 6: Total de Entradas nos Braços Fechados. Grupos que submetidos à estimulação durante o período de 8 a 35 dias. Sendo T1 e T2 referentes à $1^{\mathrm{a}}$ e $2^{\mathrm{a}}$ exposições ao LCE, respectivamente. ${ }^{*} \mathrm{p}<0,05$ em relação ao grupo desnutrido; \# p<0,05 em relação a T1 no mesmo grupo; ** p<0,05 em relação ao CHH e CEE; e *** p $<0,05$ em relação ao CEE.

Com relação aos comportamentos de levantar, houve diferenças significativas para os fatores dieta $\left(\mathrm{F}_{(1,41)}=6,18 ; \mathrm{p}<0,05\right)$ e estimulação $\left(\mathrm{F}_{(2,41)}=3,38 ; \mathrm{p}<0,05\right)$, mas não para o fator reexposição ao aparato $\left(\mathrm{F}_{(1,41)}=2,49 ; \mathrm{p}>0,05\right)$. Houve efeito da interação entre os fatores dieta e estimulação $\left(\mathrm{F}_{(2,41)}=5,05 ; \mathrm{p}<0,01\right)$.

A Figura 7 mostra que os animais desnutridos apresentaram uma freqüência menor do comportamento de levantar tanto na primeira como na segunda exposição, quando comparados com os controles $(\mathrm{p}<0,05)$. Também é possível observar que os animais que foram submetidos à estimulação apresentaram uma maior freqüência do comportamento de levantar, quando comparados com os que não foram submetidos à estimulação $(p<0,05)$, sendo que o grupo $\mathrm{CNN}$ apresenta menor freqüência de levantar comparado com o $\mathrm{CHH}$ $(p<0,05)$. 


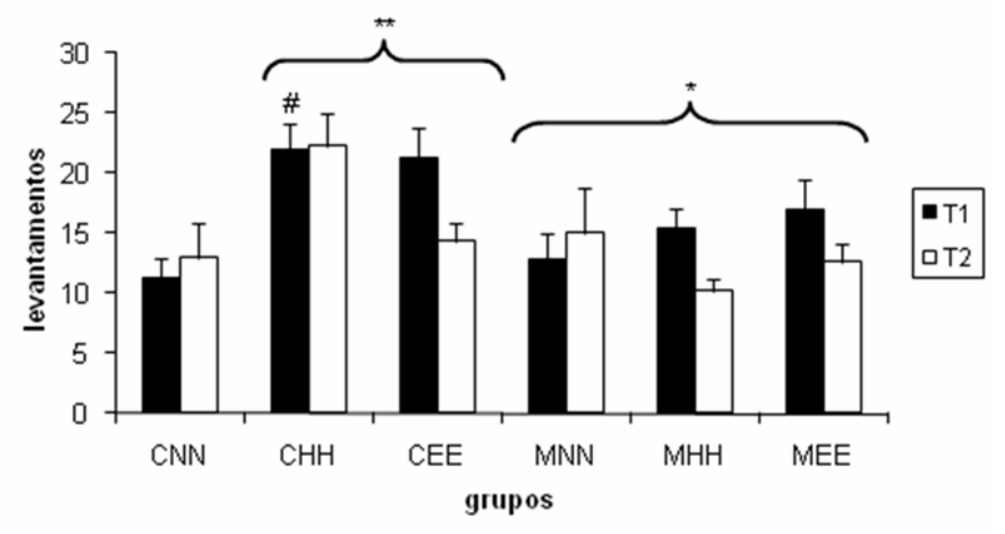

Figura 7: Número de levantamentos realizados no LCE. Sendo T1 e T2 referentes a $1^{\text {a }}$ e $2^{\text {a }}$ exposição, respectivamente. ${ }^{*} \mathrm{p}<0,05$ em relação ao grupo controle; ${ }^{*} \mathrm{p}<0,05$ em relação ao grupo $\mathrm{CNN}$; e \# $\mathrm{p}<0,05$ em relação aos grupos $\mathrm{CNN}$ e $\mathrm{MHH}$.

Com relação ao comportamento de mergulhar protegido houve diferenças significativas para os fatores estimulação $\left(\mathrm{F}_{(2,41)}=6,71 ; \mathrm{p}<0,01\right)$ e reexposição ao aparato $\left(\mathrm{F}_{(1,41)}=56,18\right.$; $\mathrm{p}<0,001)$, mas não para o fator dieta $\left(\mathrm{F}_{(1,41)}=0,12 \mathrm{p}>0,05\right)$. A ANOVA também mostrou diferenças significativas para as interações entre os fatores dieta e estimulação $\left(\mathrm{F}_{(2,41)}=3,44\right.$; $\mathrm{p}<0,05)$ e estimulação e reexposição ao aparato $\left(\mathrm{F}_{(2,41)}=8,22 ; \mathrm{p}<0,001\right)$

A Figura 8 mostra que houve um maior número de mergulhos protegidos na primeira exposição quando comparados àqueles na segunda exposição ao LCE. Também é possível notar que o grupo $\mathrm{CHH}$ apresenta um maior número de mergulhos protegidos $(8,63)$ quando comparado com os grupos CNN $(4,75)$ e CEE $(4,25)$. Os animais do grupo MEE apresentam um número menor de mergulhos protegidos $(3,00)$ quando comparados com os dos grupos $\operatorname{MNN}(6,71)$ e $\mathrm{MHH}(8,13)$. 


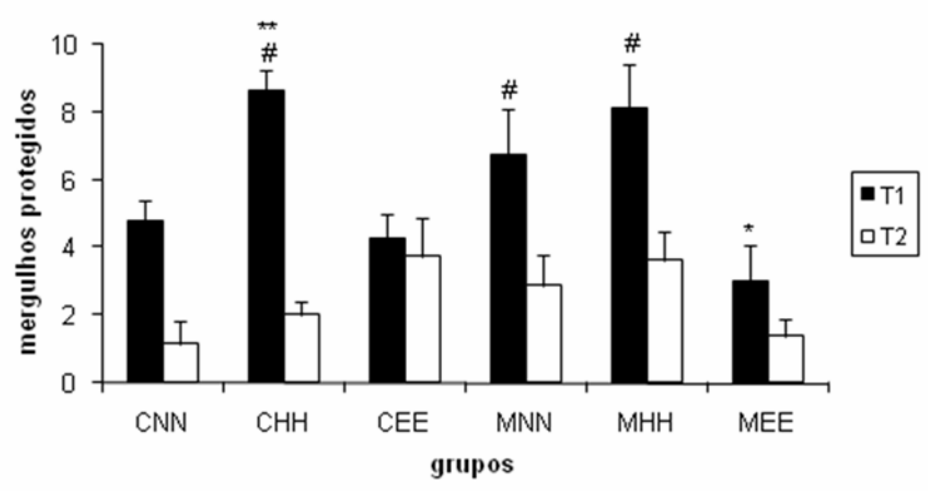

Figura 8: Número de mergulhos protegidos realizados no LCE. Sendo T1 e T2 referentes a $1^{\mathrm{a}}$ e $2^{\mathrm{a}}$ exposição, respectivamente. * $\mathrm{p}<0,05$ em relação aos grupos MNN e MHH; ** $\mathrm{p}<0,05$ em relação aos grupos CEE e CNN; \# $\mathrm{p}<0,05$ em relação a $\mathrm{T} 2$.

Já com relação aos mergulhos desprotegidos houve diferenças significativas para os fatores dieta $\left(\mathrm{F}_{(1,41)}=11,96 \mathrm{p}<0,01\right)$ e reexposição ao $\operatorname{LCE}\left(\mathrm{F}_{(1,41)}=23,93 \mathrm{p}<0,001\right)$, mas não para o fator estimulação $\left(\mathrm{F}_{(2,41)}=0,79\right.$ e $\left.\mathrm{p}>0,05\right)$. A interação entre os fatores estimulação e reexposição é significativa $\left(\mathrm{F}_{(2,41)}=7,10 \mathrm{p}<0,01\right)$

A Figura 9 mostra que os animais desnutridos têm uma freqüência de mergulhos desprotegidos maior quando comparados com os animais controle.

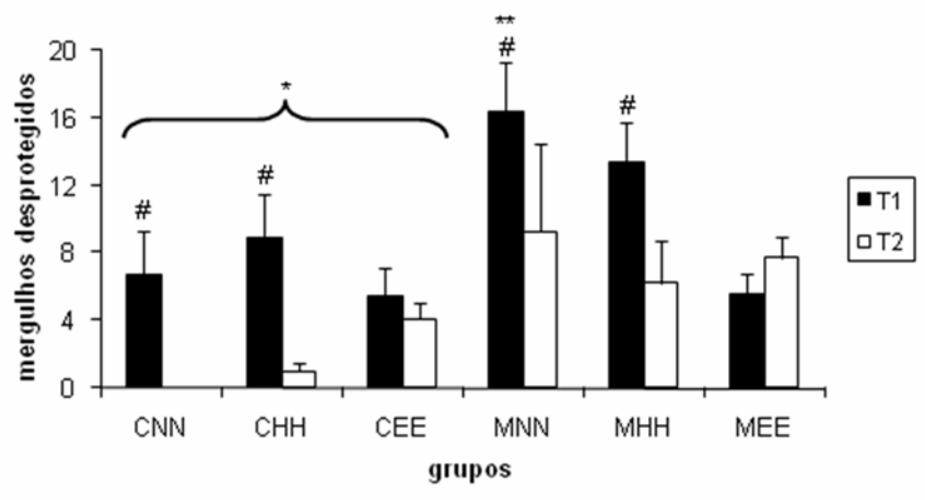

Figura 9: Número de mergulhos desprotegidos realizados no LCE. Sendo T1 e T2 referentes à $1^{\mathrm{a}}$ e $2^{\mathrm{a}}$ exposição, respectivamente. * $\mathrm{p}<0,05$ em relação aos grupos desnutridos; \# $\mathrm{p}<0,05$ em relação a T2; ** $<<0,05$ em relação a CNN. 
Com relação ao comportamento de esticar nos braços fechados, houve diferença significativa para o fator dieta $\left(\mathrm{F}_{(1,41)}=57,80 ; \mathrm{p}<0,001\right)$, mas não para os fatores estimulação $\left(\mathrm{F}_{(2,41)}=1,23 ; \mathrm{p}>0,05\right)$, e reexposição ao $\operatorname{LCE}\left(\mathrm{F}_{(1,41)}=0,001 ; \mathrm{p}>0,05\right)$ (Figura 10).

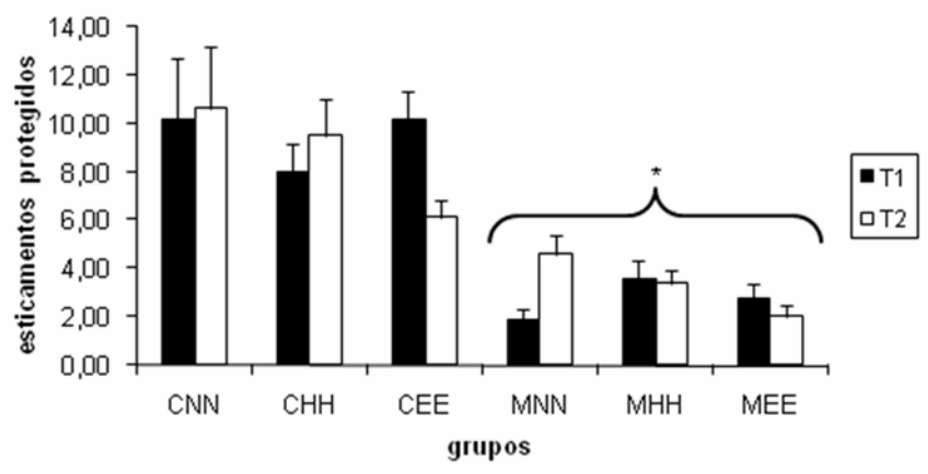

Figura 10: Número de esticamentos protegidos realizados no LCE. Sendo T1 e T2 referentes a $1^{\mathrm{a}}$ e $2^{\mathrm{a}}$ exposição, respectivamente. ${ }^{*} \mathrm{p}<0,05$ em relação aos grupos controle.

O comportamento de esticar nos braços abertos apresenta diferenças significativas para os fatores estimulação $\left(\mathrm{F}_{(2,41)}=5,01 ; \mathrm{p}<0,05\right)$ e reexposição ao $\operatorname{LCE}\left(\mathrm{F}_{(1,41)}=66,35 ; \mathrm{p}<0,001\right)$, mas não para o fator dieta $\left(\mathrm{F}_{(1,41)}=1,33 ; \mathrm{p}>0,05\right)$. Também houve diferença significativa para a interação entre os fatores dieta e exposições ao $\operatorname{LCE}\left(\mathrm{F}_{(2,41)}=8,17 ; \mathrm{p}<0,01\right)$.

É possível observar, na da Figura 11, que o grupo MHH apresenta um maior número de esticamentos $(\mathrm{p}<0,05)$ quando comparado com os outros grupos desnutridos e estimulados (MNN e MEE).

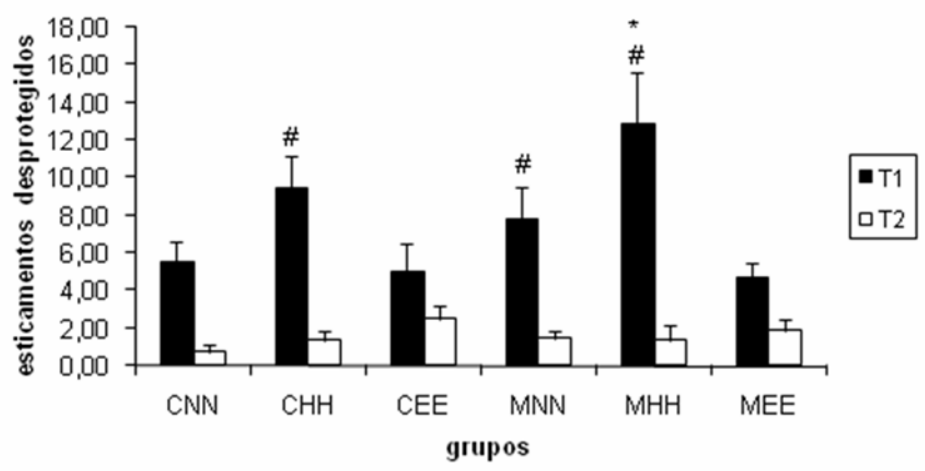

Figura 11: Número de esticamentos desprotegidos realizados no LCE. Sendo T1 e T2 referentes à $1^{\mathrm{a}}$ e $2^{\mathrm{a}}$ exposição, respectivamente. * $\mathrm{p}<0,05$ em relação aos grupos MNN e MEE; e \# p <0,05 em relação ao T2. 


\subsection{Corticosterona plasmática}

A ANOVA mostrou diferenças significativas para os fatores dieta $\left(\mathrm{F}_{(1,36)}=50,07 ; \mathrm{p}<0,001\right)$, mas não para o fator estimulação. $\left(\mathrm{F}_{(2,36)}=0,33 ; \mathrm{p}>0,05\right)$. Também houve diferença significativa para interação entre os fatores dieta e estimulação $\left(F_{(2,36)}=5,69 ; p<0,01\right)$

Na Figura 12 observa-se que os animais desnutridos apresentaram maiores níveis de corticosterona plasmática quando comparado com os animais controle, após a segunda exposição ao LCE.

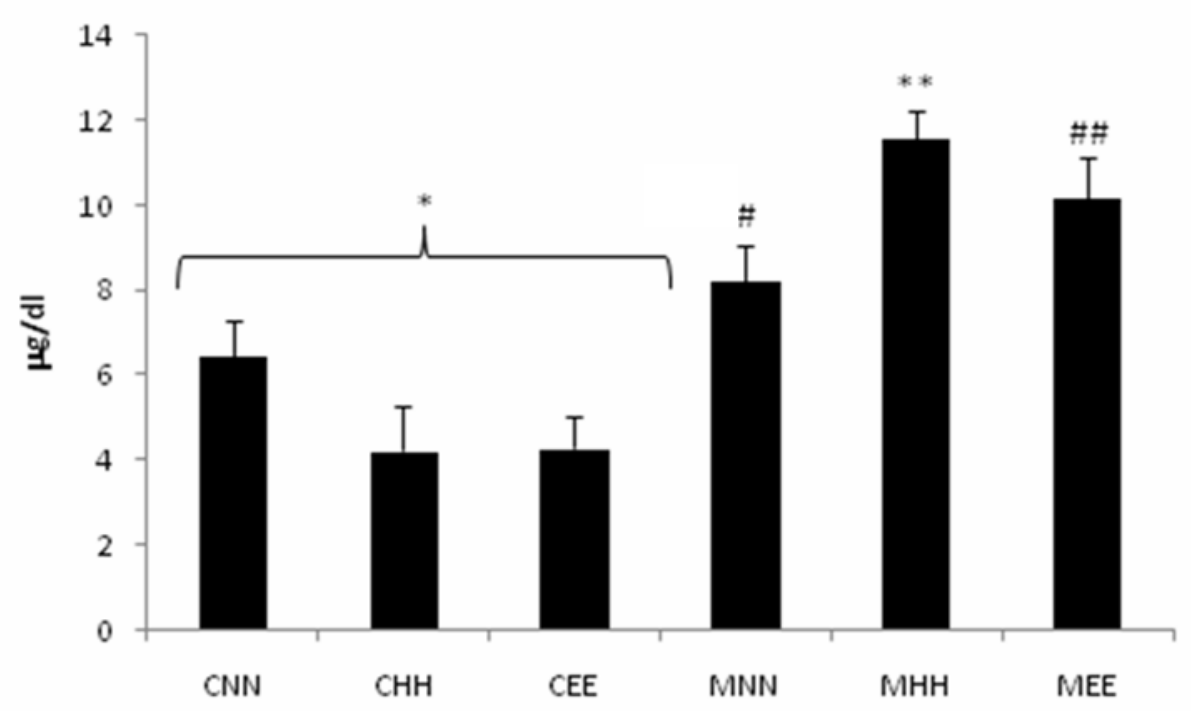

Figura 12: Corticosterona plasmática em $\mu \mathrm{l} / \mathrm{dl}$, coletada após a $2^{\mathrm{a}}$ exposição ao LCE, nos grupos submetidos à estimulação no período de 8 a 35 dias. * $\mathrm{p}<0,05$ em relação aos grupos desnutridos; ${ }^{* *} \mathrm{p}<0,05$ em relação ao $\mathrm{CHH}$; e \#\# p $<0,05$ em relação ao CEE.

\subsection{Poliaminas}

As poliaminas são o conjunto de três cátions: espermina, espermidina e putrescina. Para a analise são usados os valores de espermina, de espermidina, da soma de espermina e espermidina, e a razão entre espermina e espermidina, sendo que estes valores são expressos em $\mathrm{pMol} / \mathrm{gr}$ (tecido). A putrescina não está representada em gráfico, pelo fato de se apresentar em baixas quantidades nos tecidos coletados, impossibilitando, dessa maneira, a sua detecção pelo método utilizado. 


\subsubsection{Hipocampo}

Com relação à espermidina coletada no hipocampo, a ANOVA mostrou que houve diferença significativa para o fator estimulação $\left(\mathrm{F}_{(2,34)}=82,20 ; \mathrm{p}<0,001\right)$, mas não para o fator dieta $\left(\mathrm{F}_{(1,34)}=\right.$ $6,68 ; \mathrm{p}>0,05)$. Em relação à espermina, há diferença significativa para o fator estimulação $\left(\mathrm{F}_{(2,34)}=\right.$ $49,19 ; \mathrm{p}<0,001)$, mas não para o fator dieta $\left(\mathrm{F}_{(1,34)}=0,16 ; \mathrm{p}>0,05\right)$ (Figura 13).

A soma da espermina com a espermidina mostrou efeitos significativos para o fator estimulação $\left(\mathrm{F}_{(2,34)}=70,18 ; \mathrm{p}<0,001\right)$, mas não para o fator dieta $\left(\mathrm{F}_{(1,34)}=0,04 ; \mathrm{p}>0,05\right)$ (Figura13). A razão entre espermidina e espermina, não mostrou diferença significativa tanto para o fator $\operatorname{dieta}\left(\mathrm{F}_{(1,34)}=2,18 ; \mathrm{p}>0,05\right)$ quanto para o fator estimulação $\left(\mathrm{F}_{(2,34)}=3,09 ; \mathrm{p}>0,05\right)$ (Tabela 2$)$.

Tabela 2: Razão da espermidina e espermina (SPD/SPM), coletada após a $2^{\mathrm{a}}$ exposição ao LCE, no hipocampo, coletada após a $2^{\mathrm{a}}$ exposição ao LCE.

\begin{tabular}{cccc}
\hline & \multicolumn{2}{c}{ SPD/SPM } \\
\hline Grupos & media & \multicolumn{2}{c}{ EPM } \\
\hline CNN & 1,31 & \pm & 0,08 \\
CHH & 1,23 & \pm & 0,08 \\
CEE & 1,56 & \pm & 0,10 \\
MNN & 1,36 & \pm & 0,12 \\
MHH & 1,12 & \pm & 0,10 \\
MEE & 1,23 & \pm & 0,10 \\
\hline
\end{tabular}

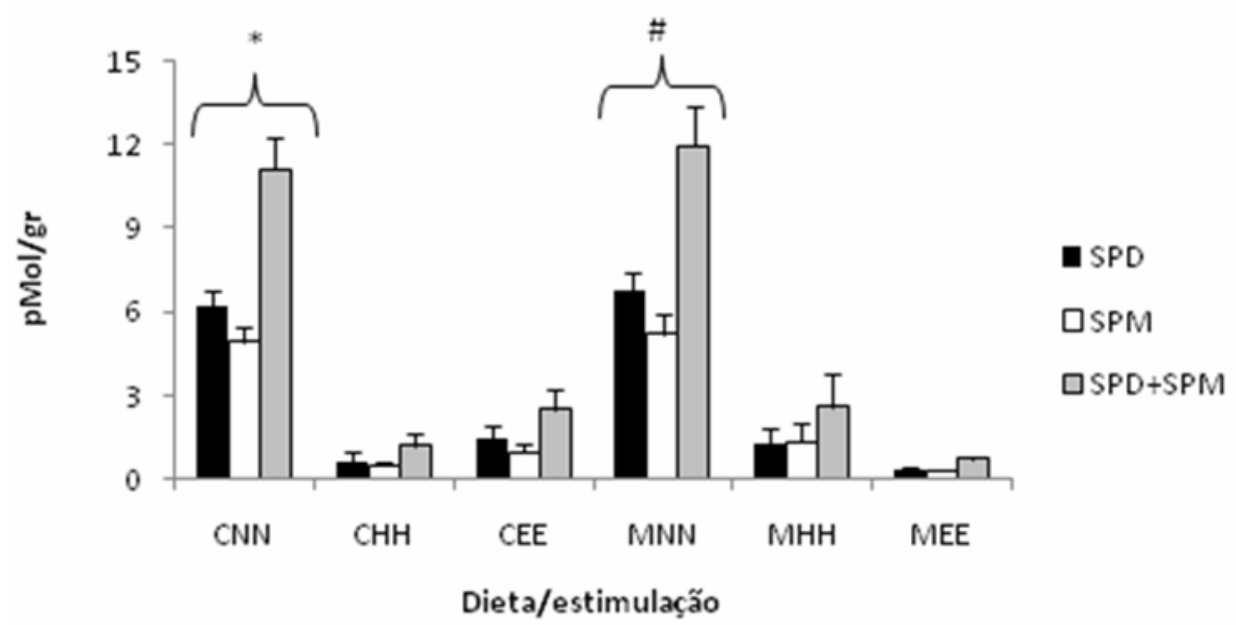

Figura 13: Valores, em pMol/g, de espermidina (SPD), espermina (SPM) e a soma de espermidina e espermina (SPD+SPM), coletada após a $2^{\mathrm{a}}$ exposição ao LCE. * ${ }^{*}<0,05$ comparado com CHH e CEE; e \# $\mathrm{p}<0,05$ comparado com MHH e MEE. 


\subsubsection{Córtex Occipital}

Com relação à espermidina a ANOVA mostrou que não houve diferenças significativas tanto para o fator dieta $\left(\mathrm{F}_{(1,41)}=0,43 ; \mathrm{p}>0,05\right)$ quanto para estimulação $\left(\mathrm{F}_{(2,41)}=0,38 ; \mathrm{p}>0,05\right)$. Da mesma maneira com relação à espermina, não mostrou diferença significativa com relação aos fatores dieta $\left(F_{(1,41)}=1,11 ; p>0,05\right)$ e estimulação $\left(F_{(2,41)}=0,64 ; p>0,05\right)$ (Tabela 3).

Já com relação à soma espermidina com espermina não mostrou qualquer diferença significativa para os fatores dieta $\left(\mathrm{F}_{(1,41)}=1,24 ; \mathrm{p}>0,05\right)$ e estimulação $\left(\mathrm{F}_{(2,41)}=0,58 \mathrm{p}>0,05\right)$. Da mesma forma com a razão SPD/SPM não houve diferenças estatísticas para os fatores $\operatorname{dieta}\left(\mathrm{F}_{(1,41)}=0,04 ; \mathrm{p}>0,05\right)$ e estimulação $\left(\mathrm{F}_{(2,41)}=0,39 ; \mathrm{p}>0,05\right)$ (Tabela 3).

Tabela 3: Valores em $\mathrm{pMol} / \mathrm{gr}$ de espermidina (SPD), espermidina (SPM), soma de espermidina e espermina (SPD+SPM) e da razão espermidina e espermina (SPD/SPM) do Córtex Occipital, coletada após a $2^{\mathrm{a}}$ exposição ao LCE.

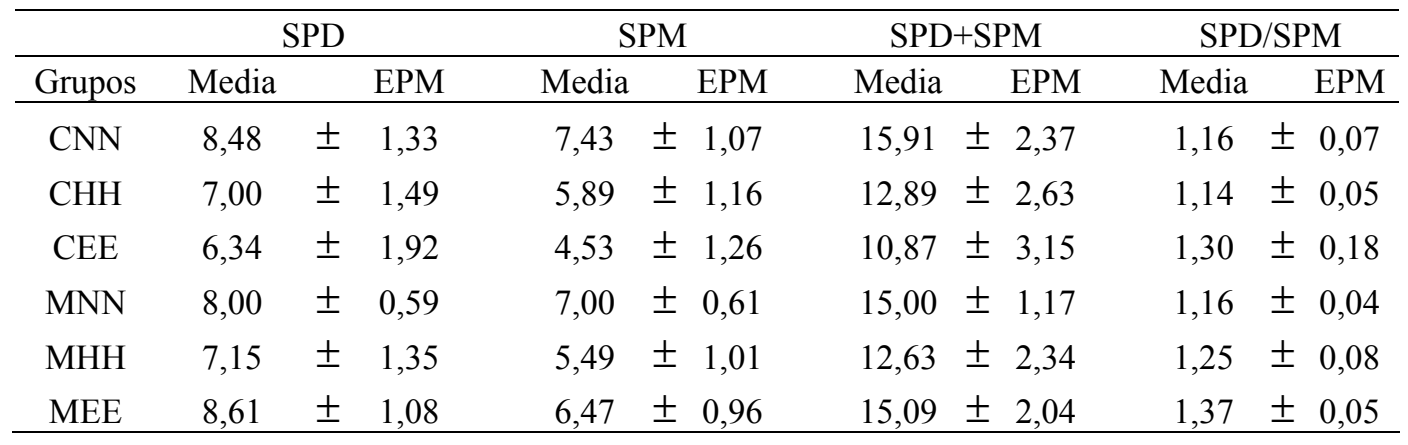




\section{DISCUSSÃO}

\subsection{Peso corporal}

A dieta hipoproteica (6\% de proteína) imposta aos animais produziu efeitos sobre seu desenvolvimento físico, como pesos significativamente menores, quando comparada com a dieta controle (16\% de proteína), conforme já descrito na literatura (de Oliveira e Almeida, 1983; Hernandes e Almeida, 2003; Silva e Almeida, 2006; Françolin-Silva et al, 2006; e Cabral e Almeida, 2008).

A partir dos dados de peso das ratas-mães, é possível observar que a dieta hipoproteica diminuiu o peso corporal das mesmas durante o período de lactação, quando comparada com a dieta controle, sendo que tal diferença é significativa a partir da primeira semana de vida das ninhadas. Possíveis explicações para a perda de peso destas ratas podem ser: o gasto da energia que esta rata pode ter tido para a produção de leite materno, o cuidado com sua prole e o fato desta ser mantida com uma dieta pobre em proteína (Dal Bello et al, 2005).

Também houve uma perda de peso das ratas-mães dos grupos controle, sendo que esta perda é mais sutil quando comparada com a perda de peso das ratas do grupo desnutrido. Sendo que a produção de leite e o cuidado com a prole, podem ser considerados possíveis explicações para este fato (Riul et al, 1999; Dal Bello et al, 2005).

A perda de peso das ratas pertencentes aos grupos desnutridos, a partir do dia 14 é mais evidente. Deve ser considerado, além do cuidado com a prole, o fato de haver competição entre mãe e filhotes em relação ao consumo de dieta disponível, pois os filhotes durante este período também se alimentam da ração experimental.

Desde a primeira semana de vida as ninhadas submetidas à desnutrição protéica apresentaram peso corporal reduzido em comparação às ninhadas controle, sendo que esta diferença se acentuou até os 35 dias de vida dos animais. Para tal diferença de peso, durante o 
período de lactação, deve ser considerado que havia uma deficiência de proteína no leite materno, em função da mãe estar sendo alimentada com uma ração pobre em proteína (6\% de proteína), o que pode ocasionar prejuízo no desenvolvimento físico do animal. (Rocinholi et al., 1997; Fukuda et al., 2002 e Fukuda et al., 2007).

É possível observar que durante o período de lactação os ratos controle e submetidos à estimulação a partir do dia 7, quando comparados com os não estimulados para a mesma condição de dieta, apresentam peso corporal significantemente menor. O fato dos animais trocarem de ambiente e interagir com objetos diferentes (enriquecimento ambiental), e interagirem em maior quantidade entre si, pode ser considerado como explicação para tal diferença de peso. Estes dados não correspondem ao que foi observado por Lima (1992), onde não houve influência da estimulação no peso dos ratos no período de lactação. Tal divergência pode se dever ao fato que no estudo de Lima (1992) o animal viva em um ambiente enriquecido, ao passo que no presente trabalho o animal era exposto por apenas 1 hora por dia ao ambiente enriquecido.

Observa-se também que no dia 21 o grupo desnutrido e submetido ao enriquecimento ambiental (ME) apresenta um maior peso corporal, quando comparado com os outros grupos na mesma condição de dieta. No período de 22 a 35 dias a desnutrição protéica alterou mais drasticamente o peso corporal dos animais desnutridos. Tais dados confirmam o que já vem sendo descrito em outros estudos, ou seja, que a desnutrição protéica quando imposta no período de desenvolvimento pode diminuir significantemente o peso corporal de ratos (de Oliveira e Almeida, 1993; Silva e Almeida, 2006; Françolin-Silva et al, 2006; Hernandes et al 2007 e Cabral e Almeida, 2008).

Desta maneira, os dados apresentados no presente trabalho mostram que o período em que a desnutrição é imposta é extremamente importante, podendo ocasionar diferentes efeitos ao organismo. De qualquer maneira a desnutrição quando imposta durante o período do 
desenvolvimento do SNC, tanto no período de lactação como no período de pós-lactação, é extremamente prejudicial podendo acarretar efeitos considerados irreversíveis (de Oliveira e Almeida, 1983; Morgane et al, 2002; Silva e Almeida, 2006).

Além dos prejuízos relacionados ao desenvolvimento físico de ratos, a desnutrição protéica pode acarretar em prejuízo para o desenvolvimento do sistema nervoso central (SNC), produzindo uma redução da ramificação dendrítica, do número de terminais sinápticos, e da mielinização em todo SNC (Lima et al, 1999). A desnutrição também pode aumentar o nível de corticosteróide circulante (Adlard e Smart, 1972).

\subsection{Labirinto em cruz elevado}

A literatura tem mostrado que a desnutrição pode provocar alterações no sistema nervoso central (Santucci et al, 1994; Cintra et al, 1997; Almeida et al, 1996; Morgane et al, 2002). O presente estudo mostrou que ratos submetidos à desnutrição protéica apresentaram um maior percentual de entradas e de tempo de permanência nos braços abertos do labirinto em cruz elevado (LCE), quando comparados a animais que não foram submetidos à restrição de proteína. Outros trabalhos já demonstraram que os animais desnutridos entram mais e permanecem mais tempo nos braços abertos do LCE quando comparados a animais bem nutridos (Almeida et al, 1993 e Fraçolin-Silva et al, 2006), sugerindo que animais desnutridos possam estar apresentando uma menor resposta de ansiedade e/ou uma maior impulsividade, nesse aparato.

A diminuição da ansiedade pode ser devido a um possível efeito da desnutrição protéica neonatal em estruturas cerebrais como o septo, o hipocampo e a amígdala, estruturas estas envolvidas na inibição comportamental (Gray e McNaughton, 2000). Desta maneira a desnutrição protéica poderia estar prejudicando a avaliação de risco em situações de ansiedade em modelos mais naturalistas de comportamento, como é o caso do LCE. 
(Hernandes e Almeida, 2003, Françolin-Silva e Almeida, 2004; Françolin-Silva e colaboradores, 2006).

Ratos desnutridos submetidos à estimulação (handling e enriquecimento ambiental) permaneceram menos tempo nos braços abertos quando comparados com animais não estimulados. A estimulação neste caso parece ter produzido um efeito protetor para as alterações comportamentais produzidas pela desnutrição protéica precoce. Essa sugestão baseia-se no fato da estimulação ambiental ter recuperado, em parte, os efeitos da desnutrição precoce de desinibir o comportamento de exploração dos braços abertos. Outros estudos já mostraram que tanto a estimulação tátil como a ambiental, podem ter um papel importante na plasticidade cerebral (Cancedda, et al, 2004; Artola, et al, 2006) e no comportamento (Morgan e Winick, 1980; Will et al 2004). Dados prévios da literatura também mostraram que o enriquecimento ambiental pode aumentar a exploração nos braços abertos do LCE (Fernandez-Teruel et al, 1990; Mcintosh et al, 1999; Santucci et al, 1994).

Os ratos desnutridos submetidos ao enriquecimento ambiental entraram e permaneceram menor tempo nos braços abertos quando comparados com os outros grupos de ratos desnutridos. Champilon e colaboradores (1999) mostraram que roedores expostos ao ambiente enriquecido apresentaram respostas relacionadas com a ansiedade diferentemente de animais não expostos ao ambiente enriquecido. Desta forma os dados mostram, em corroboração com a literatura, que o enriquecimento ambiental pode ter efeito sobre estruturas do sistema límbico como a amígdala, o hipocampo e septo (Sapolsky, 2003).

Também foi possível observar que animais submetidos ao enriquecimento ambiental, independentemente da dieta à qual foram expostos, apresentaram, na segunda exposição ao LCE, um maior número de entradas nos braços abertos quando comparados com os animais não estimulados ou submetidos ao handling. Tal fato pode ser explicado pela própria 
manipulação ambiental a que esses grupos foram submetidos durante o período de estimulação (Will et al 2004).

Com relação à porcentagem do numero de entradas e do tempo de permanência nos braços abertos, a diferença da primeira para a segunda exposição ao aparato está relacionada ao tipo de "medo". Acredita-se que a resposta de medo do rato na segunda exposição ao LCE seja de natureza diferente da resposta apresentada na primeira exposição. Alguns autores afirmam que na segunda exposição o rato apresenta o medo aprendido, sendo que na primeira o medo é inato (LeDoux, 1994; Dal-Coi et al, 2002).

Os ratos controle apresentaram um maior número de entradas nos braços fechados do LCE quando comparados aos animais desnutridos, sendo que este dado esta em conformidade com os de Almeida e colaboradores (1992). Desta forma é possível sugerir que a desnutrição protéica pode interferir na atividade locomotora de ratos (Almeida et al, 1991 e 1993). Ratos controle estimulados, independente do tipo de estimulação, apresentaram um maior número de EBF quando comparados com os ratos não estimulados na segunda exposição ao aparato, mostrando que a estimulação pode influenciar a atividade locomotora. Tal fato pode ser explicado pela própria experiência do animal na estimulação, particularmente no ambiente enriquecido onde, segundo alguns estudos, pode influenciar diretamente a locomoção e o comportamento exploratório (Renner e Rosenzweing, 1986; Will et al 2004).

Em relação ao comportamento de levantar e de esticar nos braços fechados, os ratos desnutridos apresentaram uma menor freqüência quando comparado com os ratos controle, indicando que a desnutrição pode ter ocasionado a diminuição da atividade exploratória (Almeida et al, 1991 e 1993 e Cruz et al, 1994). No entanto, existem dados que mostram que ratos desnutridos apresentam maior freqüência de levantar quando comparados com animais que não foram submetidos à desnutrição protéica (Almeida et al, 1992). 
Ratos desnutridos e submetidos ao ambiente enriquecido apresentaram um menor número de mergulhos protegidos quando comparados com os de outros grupos desnutridos. Tal diminuição pode ser atribuída à estimulação, salientando mais uma vez o caráter protetor do enriquecimento ambiental, quando realizado no período pós-natal (Levitsky e Barnes, 1972).

Já com relação aos mergulhos desprotegidos, os ratos desnutridos mergulham mais quando comparados com ratos controle, mostrando que a desnutrição pode ter influência na avaliação de risco (Hernandes e Almeida, 2003) e na diminuição das respostas de ansiedade observadas no LCE (Cruz et al, 1994 e Fraçolin-Silva et al, 2006). O ambiente enriquecido pode reverter, em parte, os prejuízos causados pela desnutrição protéica no SNC, pois ratos desnutridos e submetidos ao ambiente enriquecido apresentam praticamente a mesma freqüência de mergulhos desprotegidos, comparados com ratos controle não-estimulados (Diamond et al 1964, Rosenzweig et al, 1968; Rosenzweig et al 1996; Lima et al, 1999, Will et al 2004).

Com relação ao comportamento de esticar nos braços abertos, animais desnutridos submetidos ao handling apresentaram uma maior freqüência quando comparados com os de outros grupos desnutridos. Tal fato mostra que o handling, tal como o enriquecimento ambiental, também pode amenizar os efeitos causados pela desnutrição (Gomes et al, 1999 e Cancedda et al 2004).

\subsection{Corticosterona Plasmática}

Os níveis corticosterona plasmática podem ser alterados pela desnutrição protéica, sugerindo uma alteração da resposta adrenocortical ao estresse (Adlard, 1972), sugerindo que a desnutrição pode influenciar no eixo HPA (Kehoe et al, 2001; Duran et al 2006). Estudos mostraram que durante a desnutrição há um aumento dos níveis de corticosteróide circulante (Adlard e Smart, 1972 e Kehoe et al, 2001). 
Dados da literatura mostram que os níveis de corticosterona plasmática estão diretamente relacionados com a resposta de estresse do organismo (McCormick et al 2008). Neste trabalho, o estresse ocasionado pela desnutrição em ratos reexpostos ao LCE pode ser observado ao se comparar os níveis de corticosterona plasmática em ratos submetidos à desnutrição protéica com os níveis observados nos ratos controle. Isso mostra que a desnutrição pode influencias no funcionamento do eixo HPA, como já vendo sendo demonstrado em outros trabalhos (Almeida et al, 1996; Kehoe et al 2001; Duran et al 2006).

No entanto, a estimulação não apresentou qualquer efeito sobre os níveis de corticosterona plasmática em resposta à $2^{\mathrm{a}}$ exposição ao LCE. Sabe-se que determinados tipos de estimulação, como o handling, quando realizado no período da pós-lactação (22 a 35 dias), possui um caráter estressor (Beane et al, 2002), elevando os níveis de corticosterona em comparação aos dados de animais que não sofreram handling. Também é importante mencionar que o pico do desenvolvimento do SNC em ratos é do $7^{\circ}$ ao $14^{\circ}$ dia de vida (Morgane et al 2002), período no qual a estimulação pode ser mais eficaz (Gomes et al, 1999; Jutapakdeegul et al, 2003).

\subsection{Poliaminas}

A análise das poliaminas; espermidina (SPD), espermina (SPM), a soma de espermidina com a espermina (SPD+SPM) e razão entre espermidina e espermina (SPD/SPM), coletadas no hipocampo e no córtex occipital, permitem algumas observações. Os animais submetidos à estimulação (handling e enriquecimento ambiental), independentemente da dieta à qual foram expostos, apresentaram uma quantidade menor de SPM, SDP e SPD+SPM no hipocampo.

Tal situação pode ser entendida pelo fato da estimulação propiciar o aumento da ativação do catabolismo das poliaminas nas células do hipocampo, ocasionado pela exposição do organismo a uma situação de estresse (Gilad e Gilad, 1996; Gilad et al, 2001 e Seiler, 2004). 
Desta maneira é possível dizer que animais estimulados, independente do tipo de estimulação a que foram expostos, podem ser mais sensíveis a situações de estresse do que animais que não foram estimulados, independentemente da condição de dieta. Como o mecanismo de resposta de poliaminas ao estresse tem "caráter protetor" com relação ao estresse (Rhee, 2007), podemos dizer que a estimulação pode preparar os ratos, de maneira mais eficaz, a responder situações de estresse, favorecendo a homeostase do organismo.

Outra explicação para o nível de poliaminas diminuído em relação aos animais nãoestimulados, como está descrito em Schanberg e Field (1987), o handling, pode aumentar a síntese de ornitina descarboxilase (ODC) e, conseqüentemente, aumentar o metabolismo das poliaminas (Seiler, 2004), interferindo na síntese destas. Também pode ter ocorrido que o grupo estimulado tenha apresentado uma maior ativação do processo metabólico de poliaminas, diminuindo sua quantidade intracelular, (Seiler, 2004), mostrando que o handling pode ser tão eficaz quanto o enriquecimento ambiental, quando realizado durante o período de desenvolvimento do SNC (Duran et al, 2006; Pryce e Feldon, 2003). No entanto, pode-se dizer que o efeito protetor da estimulação frente à desnutrição protéica (Gomes et al, 1999; Jutapakdeegul et al, 2003) pode ser mais eficaz se realizada durante a lactação onde ocorre o maior desenvolvimento do SNC (Morgane et al, 2002).

Com relação ao córtex occipital o presente estudo não mostrou efeitos tanto da dieta quanto da estimulação nos níveis de poliaminas. Mostrando que o córtex occipital pode ser uma estrutura onde a desnutrição e a estimulação não tenham grande participação no anabolismo e no catabolismo de poliaminas. 
CONCLUSÕES 


\section{CONCLUSÕES}

Os dados do presente estudo sugere que a desnutrição altera o comportamento de avaliação de risco em ratos. $\mathrm{O}$ enriquecimento ambiental pode reverter, de maneira mais eficaz que o handling, os prejuízos causados pela desnutrição protéica, uma vez que ratos desnutridos, submetidos a este tipo estimulação, apresentaram comportamentos semelhante àqueles dos ratos controle no LCE. Também foi possível observar que a estimulação, independentemente do tipo, tem influência direta sobre a atividade locomotora do rato no LCE. Ratos submetidos à desnutrição protéica apresentam maiores níveis de estresse, observado através dos níveis de corticosterona plasmática após a $2^{\mathrm{a}}$ exposição ao LCE, quando comparado com ratos controle, indicando que a desnutrição pode alterar a atividade do eixo hipotálamo-hipóse-adrenal. A estimulação tanto táctil como ambiental pode alterar a resposta de poliaminas, no hipocampo durante a $2^{\mathrm{a}}$ exposição ao LCE. 


\section{REFERÊNCIAS BIBLIOGRÁFICAS}

ADLARD, B. P. F. and SMART, J. L. Adrenocortical function in rats subjected to nutritional deprivation in early life. J. Endocr. n. 54, p. 99-105, 1971.

ALMEIDA, S.S; DE OLIVEIRA, L.M; GRAEFF, F.G. Early life protein malnutrition changes exploration of the elevated plus-maze end reactivity to anxiolytics. Psychopharmacology, v. 103, p 513-518, 1990.

ALMEIDA, S.S; GARCIA, R. M.; DE OLIVEIRA, L. M. Effects of early protein malnutrition and repeated testing upon locomotor and exploratory behaviors in the elevated plus-maze. Physiology and Behavior, $v$. 54, p. 749-752, 1993.

ALMEIDA, S.S; SOARES, E.G.; BICHUETTE, M.Z.; GRAEFF, F.G.; DE OLIVEIRA, L.M. Effects of early postnatal malnutrition and chlordiazepoxide on experimental aversive situations., Physiol Behav.;v. 51(6), p. 1195-1199, 1992.

ALMEIDA, S.S; TONKISS, J.; GALLER, J.R. Malnutrition and Reactivity to Drugs Acting in the Central Nervous System. Neuroscience \& Biobehavioral Reviews, v 20, 3, p 389-402, 1996

ARTOlA, A.; VON FriJTAG, J. C.; FERMONT, P. C. J.; GISPEN, W. H; SCHRAMA, L. H.; KAMAL, A. and SPRUIJT, B. M. Long-lasting modulation of the induction of LTD and LTP in rat hippocampal CA1 by behavioral stress and environmental enrichment. European Journal of Neuroscience, Vol. 23, pp. 261$272,2006$.

BARNES, R. H. Dual role of environmental deprivation and malnutrition in retarding intellectual development. The American Journal of Clinical nutrition, n. 29, p. 912-917, 1976.

BEANE, M. L. ; COLE, M. A. ; SPENCER,R. L. e RUDY, J. W. Neonatal Handling Enhances Contextual Fear Conditioning and Alters Corticosterone Stress Responses in Young Rats. Hormones and Behavior. 41. p.33-40, 2002.

Bertoglio, L. J.; CAROBREZ, A. P., Previous maze experience required to increase open arms avoidance in rats submitted to the elevated pluz-maze model of anxiety, Behavioural Brain Research, 108, p.197-203, 2000.

BLANCHARD, D.C, BLANCHARD R. J.; RODGERS, R. J. (1991). Risk assessment and animal models of anxiety. In: Olivier B, Mos J \& Slangen JL (Editors), Animal Models in Psychopharmacology. Birkhäuser, Basel, p.117-134.

BRIAN L. G. MORGAN, B. L. G. and WINICK, A. Effects of Environmental Stimulation on Brain NAcetylneuraminic Acid Content and Behavior journal of nutrition, 1980 
BRIONES, T. L.; SUH, E.; JOZSA, L.;HATTAR, H.; CHAI, J.; WADOWSKA, M. Behaviorally-induced ultraestrutural plasticity in the hippocampal region after cerebral ischemia. Brain Res., n. 997, p. 134-146. 2004

BROZEK, J. Functional isolation in man. In: Malnutrition and behavior: Critical assessment of key issues, BROZEK, J. and SCHÜRCH, B. (ed.) Nestle foundation, v. 4, p. 424-427. 1983

BROZEK, J. Nutrição, Desnutrição e Comportamento: cadernos de pesquisa. Fundação Carlos Chagas, v. 29, p. 11-30. 1979

CABRAL, A. e ALMEIDA, S. S. Effects of tactile stimulation and underwater trauma on the behavior of protein-alnourished rats in the elevated plus-maze test. Phsychology and Neuroscience,1, 1. p. 67-72. 2008

CANCEDDA, L.; PUTIGNANO, E.; SALE, A.; VIEGI, A.; BERARDI, N.; and MAFFEI, L. (). Acceleration of visual system development by environmental enrichment. The journal of neuro.n. 19, p. 4840-4848, 2004.

CATALANI, A.;CASOLINI, P.; SCACCIANOCE, S.; PATACCHIOLI, F. R; SPINOZZI P. e ANGELUCCI, L. Maternal corticosterone during lactation permanently affects brain corticosteroid receptors, stress response and behaviour in rat progeny. Neuroscience, v. 100, 2. 2000. p. 319-325,2000.

CHAPILlON, P.; MANNECHE, C.; BELZUNG, C. ; CASTON, J. Rearing Environmental Enrichment in Two Inbred Strains of Mice: Effects on Emotional Reactivity Behavior Genetics, Vol. 29, No. 1, 1999.

CHAPILLON, P.; PATIN,. V.; ROY, V.; VINCENT, A.; CASTON, J. Effects of pre- and postnatal stimulation on developmental, emotional, and cognitive aspects in rodents: A review, Developmental Psychobiology ,41, 4, $373-387,2002$

CINTRA, L; GRANADOS, L.; AGUILAR, A.; KEMPER, T.; BASSIO, W.; GALlER, J.; MORGANE, P.; DURA' N, P. and CINTRA, S. D. Effects of prenatal Protein Malnutrition on Mossy Fibers of the Hippocampal Formation in Rats of Four Age Groups, Hippocampus,vol7, 2 p 184-191, 1997.

CRUZ, A.P.M; FREI, F.; GRAEFF, F. G. Ethopharmacollogical Analysis of Rat Behaviour on the Elevated Pluz-Maze, Pharmacol. Biochem. Behav., v. 5, 305-315, 1991.

DAL BELlO, A. C.; RIUL T. R. E DE OLIVEIRA L. M. Desnutrição e estresse na gestação: medidas comportamentias das maes e dos filhores durante a lactação. Temas em Psicologia. V 13, n1, 34-44, 2005.

DE OLIVEIRA, L. M. e ALMEIDA, S. S. Effects of Malnutrition and Environment on the acquisition an extinction of avoidance behavior in rats. Psychology and Behavior, vol 34, p. 141-145, 1993. 
DE OLIVEIRA, L. M. Malnutrition and environment: interaction effects upon animal behavior. Rev. Child. Nutr. V. 13, n. 2, p. 99-108, 1985

DIAMOND, M. C. Response of the brain to enrichment. Anais da Academia Brasileira de Ciências, 73, 211$220,2001$.

DIAMOND, M. C.; KRECH, D.; ROSENZWEIG, M. R.; The effects of an enriched environment on the rat cerebral cortex. J. Comp. Neurol., n. 123, p. 111-119, 1964.

DURAN, P.; GALLER, J. R., CINTRA, L. e TONKISS, J. Prenatal malnutrition and sleep states in adult rats: Effects of restraint stress, Phisiology and behavior, 89 p. $156-163,2006$

ELIAS, L.L., ANTUNES-RODRIGUES, J., ELIAS, P.C., MOREIRA, A.C., Effect of plasma osmolality on pituitary-adrenal responses to corticotropin-releasing hormone and atrial natriuretic peptide changes in central diabetes insipidus. J. Clin. Endocrinol. Metab. 82, p.1243-1247, 1997.

ELIAS, P.C, ELIAS, L.L., CASTRO, M., ANTUNES-RODRIGUES, J., MOREIRA, A.C., Hypothalamicpituitary-adrenal axis up-regulation in rats submitted to pituitary stalk compression. J. Endocrinol. 180, p.297-302, 2004.

ESPEJO, E. F. Effects of weekly or daily exposure to ht elevated plus-maze in male mice. Behavioural Brain Research, v. 87, p. 233-238, 1997.

FELICIANO, E. A. O Discriminações simples e complexas em ratos: efeitos da desnutrição protéica e da estimulação Tese (doutorado em psicobiologia) Faculdade de Filosofia Ciências e Letras de Ribeirão Preto, Universidade de São Paulo, Ribeirão Preto, 2007.

FEOLI, A. M.; SIQUEIRA, I. R.; ALMEIDA, L.; TRAMONTINAA, A.C.; VANZELLAC, C; SBARAINIC, S.; SCHWEIGERT, I. D.; NETTO, C. A.; PERRY, M. L. S. AND GONÇALVES, C. A. Effects of protein malnutrition on oxidative status in rat brain Nutrition, 22, p. 160-165, 2006.

FERNANDEZ-TERUEL, A.; ESCORIHUELA, CASTELlANO, B.; GONZALEZ, B.; TORBENA, A. Neonatal Handling and Environmental Enrichment Effects on Emotionality, Novelty/Reward Seeking, and Age-Related Cognitive and Hippocampal Impairments:Focus on the Roman Rat Lines, Behavior Genetics, Vol. 27, No. 6, p. 513-526, 1997.

FERNANDEZ-TERUEL, A.; ESCORIHUELA, R. M.; JIMENEZ, P. TORBENA, A. Infantile simulation and perinatal administration of Ro 15-1788 additive anxiety reduncing effects in rats. Eur. J. Pharmacol, n. 191, p. 111-114,1990.

FRANCOLIN-SILVA, A.L. e ALMEIDA, S.S. The interaction of housing condition and acute immobilization stress on the elevated plus-maze behaviors of protein-malnourished rats. Braz $\mathrm{J}$ Med Biol Res, vol.37, no.7, p.1035-1042, 2004. 
FRANCOLIN-SILVA, A.L.; Hernandes, A. S.; FUKUDA, M. T. H.; VALADARES, C. T. e ALMEIDA, S. S. Anxiolytic-like effects of short-term postnatal protein malnutrition in the elevated plus-maze test. Behv. Brain Res, v. 173, p. 310-314, 2006.

FUKUDA, M. T. H.; FRANÇOLIN-SILVA, A. L.; ALMEIDA, S. S. Early postnatal protein malnutrition affects learning and memory in the distal but not in the proximal cue version of the Morris water maze. Behavioral Brain Research, v. 133, p. 271-277, 2002.

FUKUDA, M.T.; FRANÇOLIN-SILVA, A. L.; HERNANDES, A. S.; VALADARES, C. T.; ALMEIDA, S. S. Effects of early protein malnutrition and scopolamine on learning and memory in the Morris water maze. Nutritional Neuroscience, v. 10(5-6), p. $251-259,2007$.

GILAD, G. M.; GILAD, V. H.; ELIYAYEV, Y. e RABEY, J. M. Developmental regulation of the brain polyamine stress-response. J. Devl. Neuroscience, vol 16, n. 3/4. p. 271-278, 1998.

GILAD, G.M. e GILAD, V. H. Brain Polyamine Stress Response: Recurrence After Repetitive Stressor and Inhibition by Lithium J. Neurochem. 67, p.1992—1996, 1996.

GILAD, V. H., RABEY, J. M., KIMIAGAR, Y., GILAD, G. M. The polyamine stress response: tissueendocrine-, and developmental-dependent regulation. Biochemical Pharmacology, 61, 207-213, 2001.

GLOBBO, O. L.; O'MARA, S. M.; Impact of enriched-environment housing on brain-derived neurotrophic factor and on cognitive performance after a transient global ischemia. Behv. Brain Res., n. 152, p. 231-241, 2004.

GOMES, C. M.; FRANTZ, P. J.; SANVITTO, G. L.;ANSELMO-FRANCI,J. A; LUCION, A. B. Neonatal handling induces anovulatory estrous cycles in rats. Braz. Jour. of Med. and Biol. Res. n. 32, p. 1239-1242, 1999.

GRAY, J.A.; MCNAUGHTON, N. The neuropsychology of anxiety: an enquiry into the functions of the septo-hippocampal system. 2nd ed. Oxford: Oxford University Press, 2000.

HANDLEY, S. L.; MITHANI, S. Effects of alpha-adrenoceptor agonists in a maze-exploration model of fear motivated behavior. Naunyn Schmiedeberg's archpharmacol, 327, p. 1-5,1984.

HERMEL, E.F.S.,; SEVERINO, G. S.; CECCONELLO, A. L.; PEREIRA, F. M.; SANVITO, G. L.; LUCION A. B. Neonatal handling and the expression of immunoreactivity to tyrosine hydroxylase in the hypothalamus of adult male rats. Braz. Jour. of Med. and Biol. Res. n.34, p. 1191-1195, 2001.

HERNANDES, A, e ALMEIDA, S. S. Postnatal protein malnutrition affects inhibiotory avoidance and risk assessment behaviors in two model of anxiety in rats. Nutritional Neuroscience, vol 6, 4, , p. 213-219, 2003 
HOLMES, A.; RODGERS, R. J. Responses of swiss-webester mice to repeat pluz-maze experience: further evidence for a qualitative shift in emotional state Parmachol. Sci., v. 14, p. 233-236, 1994.

JUTAPAKDEegul, N.; CASAlOTTI, S. O.; GOVITRAPONG, P.; KOTCHABAHKDI, N.; Postnatal touch stimulation acutely alters corticosterona levels and glucocorticoid receptor gene expression in the neonatal rat. Dev. Neurosci., n. 25, p. 26-33, 2003.

KEHOE, P.; MALLINSON, K.; BRONZINO, J. e McCORMICK. Effects of prenatal protein malnutrition and neonatal stress on CNS responsiveness. Developmental Brain Research, 132. p. 23-31,2001

KRECH, D.; ROSENZWEIG, M.R.; BENNETT, E.L. Effects of environmental complexity and training on brain chemistry. J Comp Physiol Psychol. Dec; 53:509-19,1960.

LEVITSKY, D. A. and BARNES, R. H. Nutrição e interação com o meio ambiente no desenvolvimento comportamental de ratos: efeitos a longo prazo. Trad. de OLIVEIRA, L. M. vol 176, p. 68-71,1972.

LIMA, J. G.; DE OLIVEIRA, L. M.; ALMEIDA, S. S. Effects of early coucurrent protein malnutrition and environmental stimulation on the central nervous system and behavior. Nutritional Neuroscience, v. 1, p. 439-448, 1999.

LIMA, J. G.; DE OLIVEIRA, L. M.; LACHAT, J. J.; DAL-BO, C. M. R. and ALMEIDA, S. S.; Comparison of the effects of lab chow and caseins diets based on body and brain development of rats. Brazilian Journal Biol. Res. n 26, p. 1069-1076,1993.

LISTER J.P., BLATT G.J., DEBASSIO W.A,. KEMPER T.L., TONKISS J., GALLER J.R., ROSENE D.L. Effect of prenatal protein malnutrition on numbers of neurons in the principal cell layers of the adult rat hippocampal formation. Hippocampus 15, p.393-403, 2005.

LISTER, R. G. The use of pluz-maze to measure anxiety in the mouse. Psychopharmacology, v. 92, p. 180$185,1987$.

LIU, Q.; SCHAFFNER, A. E.; CHANG, Y.H.; VASZIL,.K.; BARKER, J. L. Astrocytes regulate amino acid receptor current densities in embryonic rat hippocampal neurons, J Neurobiol., 33, 6, 848-864,1997.

LÖSER, C.; WUNDERLICH, U.; FÖLSH, U. R.; Reversed-phase liquid chromatographic separation and simultaneous fluorimetric detection of polyamines and theirs monoacetyl derivatives in human and animal urine, serum and tissue samples: na improved, rapid and sensitive method for routine application. Journal of Chromatography, n. 430, p. 249-262, 1988.

MATTSON, M. P.; DOU, P.; KATER, S. B. Outgrowth-regulating actions of glutamate in isolated hippocampal pyramidal neurons. J. Neurosci., n. 8, 2087-2100, 1988. 
McINTOSH, J.; ANISMAN, H.; MERALI, Z.; Short-and-long-periods of neonatal maternal separation differentially affect anxiety and feeding in adult rats: gender-dependent effects. Brain Res. Dev. Brain Res., n. 113, p. 97-106, 1999.

MEANEY, M. J.; AITKEN, D. H.; The effects of early postnatal handling on hippocampal glucorticoid receptor concentrations temporal parameters. Develop. Brain Res. N. 22, p. 301-304, 1985.

MESQUITA, R. M., PEREIRA, P. A., \& ANDRADE, J. P. Low levels of brain-derived neurotrophic factor and tyrosine kinase receptor $B$ are related to loss of dentate granule cells after prolonged low-protein feeding in the rat. Neuroscience Letters, 330, 155-158. 2002

MONTGOMERY, K. C. the relationship between fear induced by novel stimulation and exploratory behaviour. Journal Comp. Pschl., 48 p. 254-260, 1955.

MORGANE PJ, AUSTIN-LAFRANCE RJ, BRONZINO JD, TONKISS J, GALLER JR. Malnutrition and the developing central nervous system. In: Isaacson, RL, Jensen KF, editors. The vulnerable brain: nutrition and toxins.New York: Plenum Publishing Corporation;. p. 3-44. 1992.

MORGANE, P. J.; MOKLER, D. J and GALLER, J. R. Effects of prenatal protein malnutrition on the hippocampal formation. Neur. And Behav. Reviews., n. 26, p. 471-483,2002

NETTO, C. A.; HODGES, H.; SINDEN, J. D.; LE PEILLET, E.; KERSHAW, T.; SOWINSKI, P.; MELDRUM, B. S.; GRAY, J. A. Foetal grafts from hippocampal region superior alleviate ischaemic-induced behavioral deficits. Behav. Brain Res., n. 58, p.107-112, 1993.

PASSINEAU, M.J.; GREEN, E.J., DIETRICH, W.D. Therapeutic Effects of Environmental Enrichment on Cognitive Function and Tissue Integrity Following Severe Traumatic Brain Injury in Rats Experimental Neurology, 168, 2, 12, pp. 373-384, 2001

PELLOW, S. ; CHOPIN, P.; FILE, S. E. \& BRILEY, M. Validation of open: closed arm entriens in the elevated pluz-maze e as measure of anxiety in the rat, Pharmacology Biochemistry and Behavior, n. 24, p. $525-529,1985$.

PEREIRA, L. O; ARTENI, N. S..; PETERSEN, R. C.; DA ROCHA, A. M.; ACHAVAL, M. E NETTO, C. A. Effects of daily environmental enrichment on memory defficitsand brain injury following neonatal hypoxia-ischemia in the rat, Neurobiology of Learning and Memory, vol 87, 1 p. 101-108, 2006.

PHAM, T. M.; SÖDERSTRÖM, S.; WINBLAD, B.; MOHAMMED, A. H.; Effects of environmental enrichment on cognitive function and hipocampal NGF in the non-handled rats. Behav. Brain Res. N. 103, p. 63-70, 1999. 
PINHEIRO, G. de A.; ALVES, S. H. de S. ; MURCE P. P. ; CRUZ, A. P. de M., Envolvimento dos receptores 5-HT2 da amígdala nos níveis de ansiedade induzidos pela exposição de ratos ao labirinto em cruz elevado, Psicologia: Teoria e Pesquisa, vol 18. n. 3, p. 329-335, 2002.

PRYCE, C. R. e FELDON, J. Long-term neurobehavioural impact of the postnatal environmental in rats: manipulations, effects and mediating mechanisms. Neuroscience and behavioral reviews, 27, p. 57-71, 2003.

RAINNIE, D. G., Serotorninegic Modulation of Neurotransmission in the rat basolateral amygdala., Journal of Neurophisiology, 82: p. 69-85, 1999.

RENNER, M. J. e ROSENWEING, M. R. Social interactions among rats housed in grouped and enriched conditions. Developmental Psychobiology. V 19, 4, p. 303-313, 1986

RHEE, H. J.; KIM, E. J. e LEE, J. K. Physiological polyamines: simple primordial stress molecules. Journal Cell. Med., vol 11, n 4. p. 685-703, 2007.

RIUL, T. R.; CARVALHO, A. F.; ALMEIDA, P. S.; DE OLIVEIRA, L. M. and ALMEIDA, S. S. Ethological analysis of mother-pup interactions and other behavioral reactions in rats: effects malnutrition and tactile stimulation of the pups. Braz.. Journal of Med. and Bio. Res., n. 32, p. 975-983, 1999.

ROCINHOLI, L. F.; ALMEIDA, S. S.; DE OLIVEIRA, L.M. Response threshold to aversive stimuli in stimulated early protein-malnourished rats. Brazilian Journal of Medical and Biological Research, v. 30, p. 407-413, 1997.

RODGERS, R. J. ; CAO, B. J. ; DAVI, A. and HOLMES, A. Animal models of anxiety an ethological perspective., Brazilian Journal of medical and Biological Research, v.30 p. 289-304, 1997

RODGERS, R. J.; SHEPHERD J. K., Influence of prior maze experience on behaviour and response to diazepam in the elevated pluz-maze and light-dark test of anxiety in mice, Psychopharmacology, 113 (2), p. 237-242,1993.

RODRIGUES, A. L.; ARTENI, N. S.; ABEL, C.; ZYLBERSTEJN, D.; CHAZAN, R.; VIOLA, G.; XAVIER, L.; ACHAVAL, M.; NETTO, C. A. Tactile simulation and maternal separations prevent hippocampal damage in rats submitted to neonatal hypoxia-ischemia., Brain Res. N. 1002, p. 94-99, 2003

ROSENZWEIG, M. R. and BENNETT E. L. Psychobiology of plasticity: effects of training and experience on brain and behavior. Beh. Brain Res. N. 78, p. 57-65, 1996

ROSENZWEIG, M. R.; LOVE, W.; BENNETT E. L. Effects of a few hour a day of enriched experience on brain chemistry and brain weights. Psychology and behavior, v. 3, p. 819-825. 1968. 
SANTUCCI, L. B.; DAUD, M. M.; ALMEIDA, S. S. and de OLIVEIRA, L. M.; Effects of early protein malnutrition and environmental stimulation upon the reactivity to diazepam in two animal models of anxiety. Pharmacology Biochemistry and Behaviour.. V 49, n. 2, p. 393-398, 1994.

SAPOLSKY, R. M. A Mechanism for Glucocorticoid Toxicity in the Hippocampus: Increased Neuronal Vulnerability to Metabolic Insults The Journal of Neuroscience Vol. 5, No. 5, pp. 1228-1232, 1985.

SAPOLSKY, R. M. Stress and Plasticity in the Limbic System. Neurochemical Research, Vol. 28, No. 11, p. $1735-1742,2003$

SCHERTEL, B., E EICHLER, W. Polyamine biosynthesis in arginine-starved and refed rats. Biological Chemistry Hopper-Seyler, 372, 27-33, 1991.

SEILER, N. Catabolism of polyamines. Amino acids, 26, p. 217-233, 2004.

SHANBERG, S. M.; FIELD, T. M. Sensory deprivation Stress and supplemental stimulation in the rat pup and pretern humam neonate. Child Development. V. 58, p. 1431-1447,1987.

SILVA, M. S. P. e DE OLIVEIRA, L. M. Desnutrição e níveis de aminas biogênicas no sistema nervoso central. Rev. Soc. Bras. Alim. Nutr. V. 79, p. 75-97, 2005.

SMART JL, ADLARD BP, DOBBING J. , Further studies of body growth and brain development in "small-for-dates" rats. Biol Neonate ;25 (3-4):p.135-50, 1974

SMART, J. L. Early life malnutrition and later learning ability: A critical analysis, in Genetics Environment and intelligence, Oliverio, A. (eds) Amsterdam, p. 215-267; 1977.

SMYTHE J.W., ROWE W.B., MEANEY M.J. Neonatal handling alters serotonin (5-HT) turnover and 5HT2 receptor binding in selected brain regions: relationship to the handling effect on glucocorticoid receptor expression, Brain Res Dev Brain Res. 1994 Jul 15;80(1-2): p.183-9, 1994.

TEJEDOR-REAL P, COSTELA C, GIBERT-RAHOLA J. Neonatal handling reduces emotional reactivity and susceptibility to learned helplessness. Involvement of catecholaminergic systems, Life Sci. 62(1):37-50, 1998

UNICEF Situação Mundial da Infância, Brasília: Unicef, 1998.

UNICEF The State Of The World's Children, Unicef, 2007. 
WAINWRIGHT, P.E.; COLOMBO, J. Nutrition and the development of cognitive functions: interpretation of behavioral studies in animals and human infants, American Journal of Clinical Nutrition,84, p. 961-970, 2006.

WAllaCE, H. M., FRASER, A. V., HUGHES, A. A perspective of polyamines metabolism. Biochemical Journal, 376, 1-14, 2003.

WIGGER, A.; NEUMANN, I.D. Periodic maternal deprivation induces gender-dependent alterations in behavioral and neuroendocrine responses to emotional stress in adult rats. Physiol Behav.;66 (2):293-302, 1999.

WILL, B.; GALANI, R.; KELCHE, C. E ROSENZWEIG, M. R. Recovery from brain injury in animals: relative efficacy of environmental enrichment, physical exercise or formal training (1990-2002). Progress in Neurobiology, n. 72, p. 167-182, 2004.

WOOD, D. A.; BUSE, J. E.; WELLMAN, C. L. E REBECT, G. V. Differential environmental exposure alters NMDA but not AMPA receptor subunit expression in nucleus accumbens core and shell. Brain Research, 1042, p. 176-183, 2005. 